Portland State University

PDXScholar

$1-18-1984$

\title{
A Comparison of Measures of Emotions From Written Reports of Dreams and Waking Experiences
}

\author{
Edward D. Conklin \\ Portland State University
}

Follow this and additional works at: https://pdxscholar.library.pdx.edu/open_access_etds

Part of the Cognitive Psychology Commons

Let us know how access to this document benefits you.

\section{Recommended Citation}

Conklin, Edward D., "A Comparison of Measures of Emotions From Written Reports of Dreams and Waking Experiences" (1984). Dissertations and Theses. Paper 3381.

https://doi.org/10.15760/etd.5251

This Thesis is brought to you for free and open access. It has been accepted for inclusion in Dissertations and Theses by an authorized administrator of PDXScholar. Please contact us if we can make this document more accessible: pdxscholar@pdx.edu. 
AN ABSTRACT OF THE THESIS OF Edward D. Conklin for the Master of Science in Psychology presented January 18, 1984.

Title: A Comparison of Measures of Emotions from Written Reports of Dreams and Waking Experiences

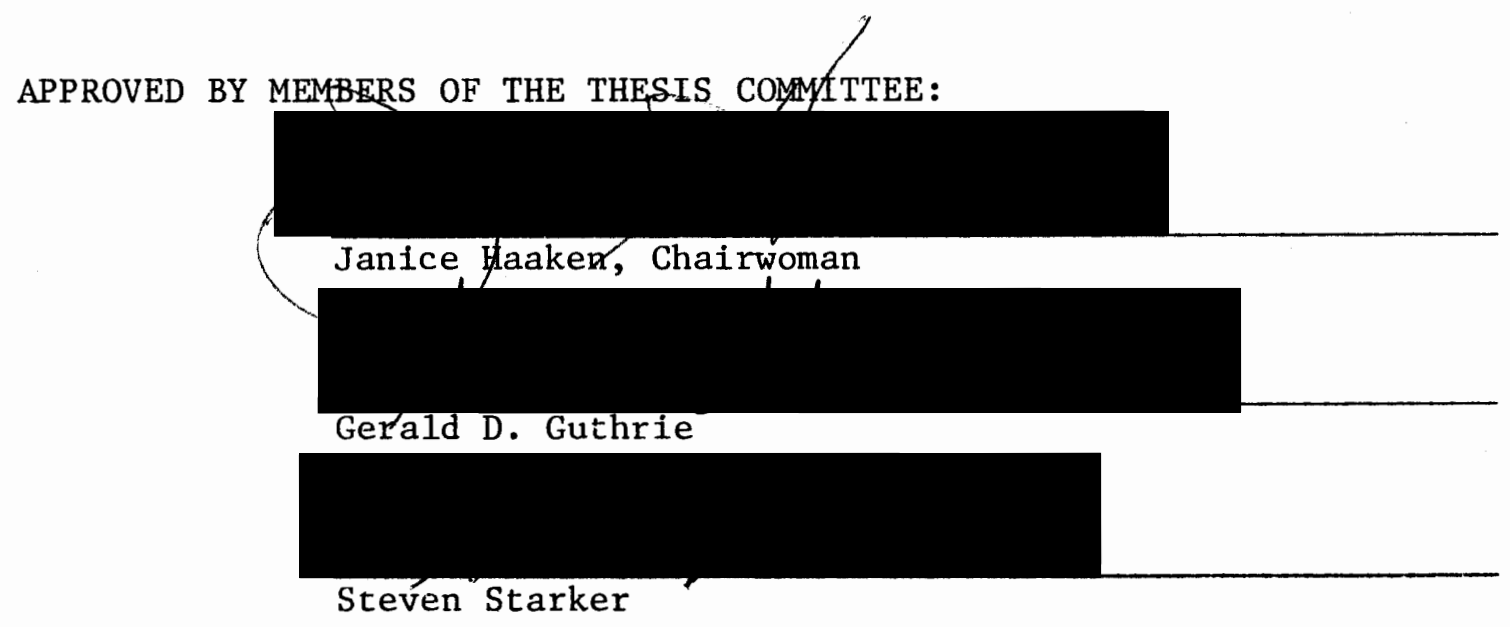

Various researchers have noted that emotions expressed in dream reports are infrequent and, more often, unpleasant. These observations are ambiguous for several reasons: (1) Empirical opinions differ markedly with regard to the structure of mentation across the continuum of waking and sleeping experience. (2) While the waking state is usually assumed as an implicit baseline, few studies have quantitatively compared waking and dream emotions. (3) Dream researchers have not thought about the basic nature of emotions or certain constraints which sleep physiology might impose upon emotions. In light of these assertions and considerations, an intrasubject comparison of emotions in reports of waking experiences and dreams might seem worthwhile. 
In this study nine female university students wrote about their waking experiences for the four hour period prior to going to sleep during a two week period. On alternate mornings, these subjects either redescribed the prior evening's events or described any dreams they remembered. The procedures and formats for the evening and morning reports were as nearly equivalent as practical considerations allow.

Two judges scored all reports for five classes of emotions defined by Hall and Van de Castle (1966). Interrater agreement was weak. The respective judges seemed to employ more or less stringent standards in identifying emotions. This fact notwithstanding, the ultimate findings, based on each judge's independent scores, point to the same conclusion.

The results seem to contradict assertions that dreams exhibit fewer or more dysphoric emotions. Overa11, reports of waking experiences and dreams contained the same frequencies and qualities of emotions. While this describes the bulk of the findings, there is a suggestion that reports from certain individuals may exhibit different emotions in reports of the two states. 
A COMPARISON OF MEASURES OF EMOTIONS FROM WRITTEN REPORTS OF DREAMS AND WAKING EXPERIENCES

by

EDWARD D. CONKLIN

A thesis submitted in partial fulfillment of the requirements of the degree of

\author{
MASTER OF SCIENCE \\ in \\ PSYCHOLOGY
}

Portland State University 
TO THE OFFICE OF GRADUATE STUDIES AND RESEARCH:

The members of the Committee approve the thesis of Edward D. Conk1in presented January 18, 1984\%
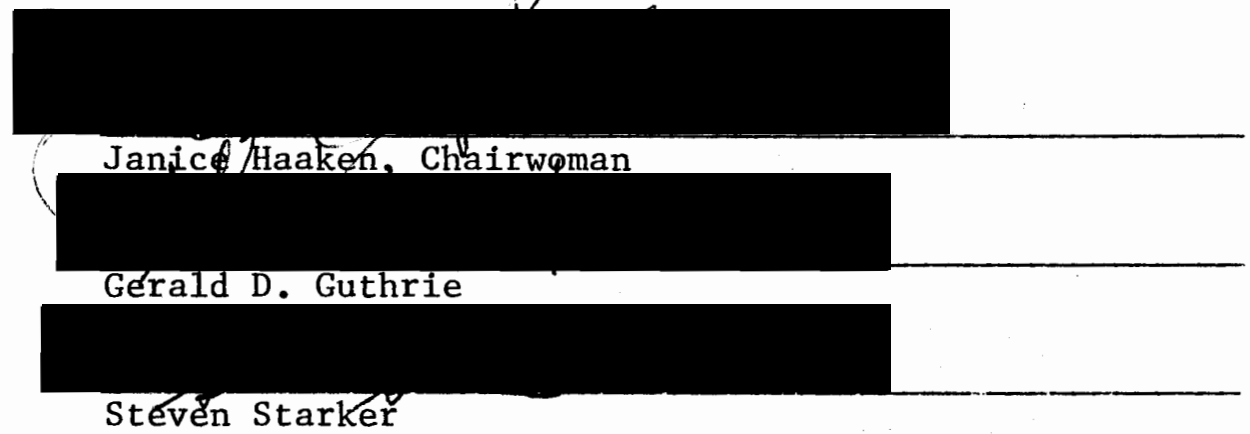

APPROVED:

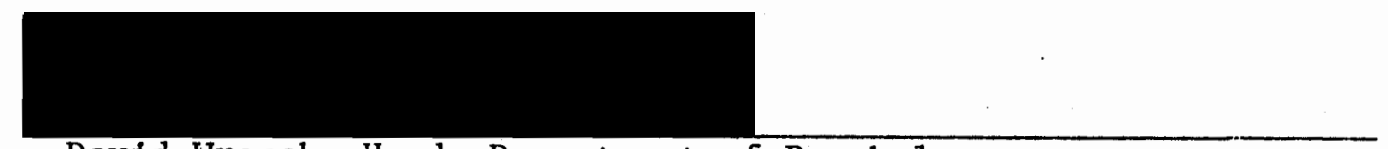

David Wrench, Head, Department of Psychology

Stanley E. Rauch, Dean of Graduate Studies and Research 


\section{ACKNOWLEDGEMENTS}

I want to acknowledge four people's contributions to this project. The gentle expertise of my committee, Dr. Janice Haaken, Dr. Gerald Guthrie, and Dr. Steven Starker, was an invaluable guide. Thanks, a11 of you.

The patience, help, and wisdom of my lovely wife made a tough job much easier. Karen, I love you. 
TABLE OF CONTENTS

PAGE

ACKNOWLEDGEMENTS .................. . . $i$...

LIST OF TABLES ............................. vi

LIST OF FIGURES .................... vii

CHAPTER

I INTRODUCTION ..................... 1

II THE COMPARISONS OF DREAMS AND WAKING EXPERIENCE . . . . 2

Assumption of Waking Experience as a Baseline ..... 2

The Relationship Between Waking and Sleeping

Experience ................ 2

III RESEARCH ON EMOTIONS IN DREAM REPORTS . • • • . . . 7

Dreams Express Fewer and More Unpleasant Emotions • . 7

Dreams Vent Emotions ............ 10

Dream Emotions Parallel Waking Emotions . . . . . 10

Four Recent Studies: Findings and Methodological

Issues . . . . . . . . . . . . . 11

IV EMOTIONS IN DREAMS . . . . . . . . . . 20

Theories of Emotions . . . . . . . . . 20

Emotions and Sleep Physiology .......... 26

V METHODOLOGY OF DREAM RESEARCH . . . . . . . . 35

Subject Factors ............. 35

Procedural Factors . . . . . . . . . 38

VI SUMMARY OF CHAPTERS I THROUGH V . . . . . . . . 45 
DESCRIPTION OF THE PRESENT STUDY . . . . • . . . . • •

Statement of Purpose and Prospectus . . . . . . . . 47

Method ...................... 48

Subjects

Procedures

Data Collection

Scoring

Results . . . . . . . . . . . . . . . . . .

Raters

Reports

Discussion of Results . . . . . . . . . . . 60

Conclusions . . . . . . . . . . . . . . 63

REFERENCES . . . . . . . . . . . . . . . . . . . 65

APPENDICES

A SLEEP AND DREAM-HABITS QUESTIONNAIRE . . . . . . . . . . . 72

B INFORMED CONSENT FORM . . . . . . . . . . . . . 75

C INSTRUCTIONS TO SUBJECTS . . . . . . . . . . . . . . . 77

D SCORING CRITERIA SUMMARY • . • . . . . . . . . . . . 79

E NOTES FOR SCORERS . . . . . . . . . . . . . . 82

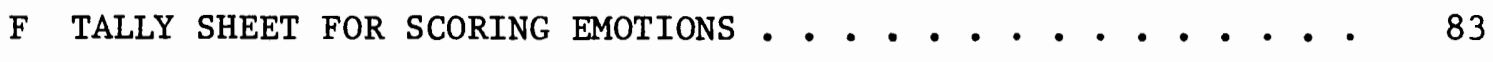




\section{LIST OF TABLES}

PAGE

TABLE

I Summary of Frequency Counts for Five Classes of Emotions and Total Emotions for $\underline{N}=252$ Reports and Pearson's $\underline{r}$ Values for Two Raters ............... . 57

II T-Tests of Differences in Correlated Mean Frequencies and Rates of Total Emotions Per Report Comparing Type 1 With Type 3 and Type 2 with Type 4 Reports ...... 58

III T-Tests of Differences in Correlated Mean Word Counts Comparing Report Types Using Data From All Subjects . . . 59

IV T-Tests of Differences in Correlated Mean Frequencies or Rates, Where $\mathrm{p}<.05$, for Five Classes of Emotions Comparing Evening and Subsequent Morning Report Types . • 


\section{LIST OF FIGURES}

PAGE

FIGURE

1. Data Collection Procedure Showing Report Types for Odd and Even Numbered Subjects . . . . . . . . . . . 


\section{CHAPTER I}

\section{INTRODUCTION}

Various researchers have observed that dream reports expressed fewer emotions (Calkins, 1893; Hall \& Van de Castle, 1966; Snyder, 1970; Hartshorn, Corriere, Karle, Switzer, Hart, Gold, \& Binder, 1977) and more unpleasant emotions (Calkins, 1893; Weed \& Hallam, 1896; Bentley, 1915; Hal1 \& Van de Castle, 1966; Snyder, 1970; Kramer, Winget, \& Whitman, 1971) than they expected. These observations might imply that dream reports contain less emotions and more dysphoric emotions than would reports of waking experiences. However, the studies cited did not evaluate waking reports.

In this project five classes of emotions were scored for similar reports of dreams and waking experiences, and these measures were compared to see if they are different. In general, the results are inconsistent with the implications suggested above.

As preface to describing the present research, the relationship between dreams and waking experience and some relevant additional empirical findings about dreaming and waking emotions are discussed. Theories of emotions and certain constraints which sleep physiology might impose on dream emotions are considered. Finally, methodological issues are identified. 
CHAPTER II

THE COMPARISON OF DREAMS AND WAKING EXPERIENCE

ASSUMPTION OF WAKING EXPERIENCE AS A BASELINE

The assumption of waking experience as "given" and as a baseline against which to compare dreams influences conceptualization of dreams and probably dream research. In this perspective, memories from sleep may be described as more bizarre, hallucinatory, symbolic, and less rational than waking experiences. The reasoning behind this assumption is usually tacit and merits examination. Maybe we employ wakeful experience as a baseline because it seems more "normal," is more easily remembered (see Domhoff, 1969; Cohen, 1974), or we feel that we understand it better. It could be that we do not use sleeping experience as a baseline because we almost always make comparisons of the two states when we are awake; were we to evaluate waking experience when asleep, that state might seem the more normal. In any event a point made by Foulkes and Fleisher (1975) is critical:

[The] baseline properties of waking thought can no longer be assumed in studies of sleep mentation. Rather they must be independently studied with techniques comparable to those used in sleep studies. (p. 74)

The present study attempted to honor this requirement.

THE RELATIONSHIP BETWEEN WAKING AND SLEEPING EXPERIENCE The relationship between waking and sleeping experience has received extensive empirical and theoretical attention. The 
following selections highlight some predominant thinking in this

area.

[Cartwright (1969) maintains] most current dream theory can be clustered into one of two positions: the Freudian and Alderian. The Freudian view sees the dream as providing disguised gratification of individual wishes which are denied awareness during wakefulness. In the Alderian view, dreams seem to be motivated by the need for a solution to current emotional problems from our waking life and conscious experience. These two imply opposite types of relationships between dreaming and the conscious waking behavior which precedes it: the first implies a compensatory, the second a continuity relationship. (pp. 366-367)

Schwartz, Weinstein, and Arkin (1978) debate the positions assigned by Cartwright to the various theoretical schools. Nevertheless, the degree to which sleeping mentation is or is not continuous with waking mentation, while categorized or articulated differently by many authors (e.g., Foulkes, 1962; Tomkins, 1962; Singer, 1966; Beck, 1969; Starker, 1974; Schwartz et al., 1978; Vogel, 1978), seems to be a recognized and reasonable point of departure in describing and perhaps better understanding the nature of dreams.

Beck (1969) reorganized "the assumptions underlying contemporary dream theories" (p. 373) into (1) a continuity-discontinuity position, (2) a functional position where dreams fulfill wishes (Freud) or solve problems (Adler, French, Hall, \& Fromm), and (3) a category where dreams serve no function. Under his functional proposition, Beck describes a "congenitive model of dreams" (p. 375) where idiosyncratic cognitive patterns are activated during waking experience and influence an individual's interpretation of reality. When the patient is asleep and external stimuli are absent, the schemata (patterns) exert a maximum influence on the thinking, as manifest in the thematic content of dreams . . . [This mode1] not only bridges the gap between sleeping mentation and waking mentation 
but remains clear of the teleological overtones contained in the theory that dreams serve as a guardian of sleep or solve problems. (pp. 375-376)

While Beck may or may not ascribe some esoteric operant function to dreaming, his is a continuity position in viewing mentation as a relatively constant structure across time, waking and sleeping, for a given individual.

Schwartz et al. (1978) discuss and expand on Cartwright's and Beck's presentations. They feel that

the assumptions of contemporary dream theory are best presented in terms of two categories . . . the Function-of-Dreaming Category [in which ] dreams play a role in adaptational processes . . [ [such as coping or problem solving, information processing] . . . development, regulation and/or maintenance of cognitive, self, or ego systems [and sleep preservation, or that dreams serve no function but are only] the expression of psychic activity during sleep. (pp. 222, 223)

Schwartz et al. cite various authors who subscribe to their "Adaptational processes" functions. Their second category is "The ContinuityDiscontinuity-between-Dreaming-and-Wakeful-Mentation Category" (p. 223). In response to Cartwright's contention that the discontinuity position is represented in the Freudian view, Schwartz et al. cite Freud (1960) to contend

that Freud's model of dream formation quite nicely allows for both continuity and discontinuity between dreams and wakeful mentation as well as manifest-dream events which deal with problem solving, coping, and adaptation. (p. 223)

In a nutshe11, Freud recognized a "'secondary' function of dreams,"

not considered in "dream-interpretation," which includes

thinking ahead, forming intentions, framing attempted solutions which may perhaps be realized later in waking life, all these, and many other similar things, are products of the unconscious and preconscious activity of the mind; they may persist in the state of sleep as "the day's residues" and combine with an unconscious wish. . . in forming a dream. (Freud, 1960, pp. 618-619) 
As I read it, this secondary function may reflect an onging or continuous process while, at the same time, the unconscious wish with which it combines may represent a distinct, discontinuous element. Schwartz et al. conclude, however, that verification of the Freudian position is "well nigh impossible" (p. 224).

In examining the relationship between daydreaming and nocturnal dreaming, Starker (1974) describes three models: (1) alternative channels, (2) analagous or parallel processes, and (3) independent processes. Tomkins (1962) and Singer (1966) have also described analagous, parallel, or continuum positions. The independent processes argument is summarized well by Vogel (1978). Many studies specifically address the relationship between waking and sleeping fantasy, but the various paradigms might be extended to other comparisons of the waking and sleeping states.

While different arguments emphasize continuous, discontinuous, or functional elements, some basic concepts seem to prevail: (1) Dreaming and waking mentation are seen as similar if not identical; or (2) each state exhibits functions which are, for unknown reasons, either impossible, inoperative, or operate differently in the other. In the latter case, dreaming may or may not somehow counterbalance waking mentation.

The consciounsness continuum is not easily fragmented. So called continuous, discontinuous, and functional events are not discreet. Foulkes (1962) points out that "mental activity is always present in the sleeping human" (p. 24). Cartwright (1969) maintains that such activity is pursued differently under different states. 
Cohen (1974) refers to

evidence that to a certain extent adaptive personal functioning continues during sleep and is represented in dream content (Bonime, 1962; Breger, 1967; Cohen, 1973 b; Dewan, 1969; Ha11, 1966; Shulman, 1969). (p. 138)

In short, while the various continuity, compensatory, and functional constructs can prove heuristically useful, they may make complex, multifaceted functions seem unidimensional. 
Certain findings have been interpreted to support contentions that (1) emotions are infrequent and more often dysphoric in dreams, (2) dreams vent emotions, or (3) dream emotions are no different than waking emotions. Research methods may well influence these seemingly different conclusions. This chapter describes some studies which support the three contrasting views and considers some relevant methodological issues in light of four more recent investigations.

\section{DREAMS EXPRESS FEWER AND MORE UNPLEASANT EMOTIONS}

As previously noted, Calkins (1893), Hall and Van de Castle (1966), Snyder (1970), and Hartshorn, et al. (1977) noted a paucity of incidence while Calkins (1893), Weed and Hallam (1896), Bentley (1915), Hall and Van de Castle (1966), Snyder (1970), and Kramer, et al. (1971) saw a dysphoric tone in the apparent emotions of dream reports. The following section describes three of these studies.

Hall and Van de Castle (1966) developed a system for classifying and scoring eight variables from written dream protocols. They found that "the classification of emotions was one of our most difficult tasks" (p. 110). Furthermore:

When a scorer goes over dream reports he is generally surprised at how few emotions are actually reported, unless the dreamer is specifically and strongly urged to state what emotions he experienced during the dream. Situations that would undoubtedly be terrifying or depressing for the average 
individual may be reported in some detail, but a description of their emotional impact upon the dreamer is of ten curiously lacking. (p. 110)

They also note that "good fortunes are rather rare in dreams" (p. 106); and when emotions are identified by the dreamer, "negative emotions, i.e., sad, angry, confused, and apprehensive, predominate over happiness" (p. 193).

Snyder (1970) studied verbal reports from REM awakenings. He points out that most researchers agree dreaming has an emotional dimension and cites Weed and Hallam (1896) and Bentley (1915) who found unpleasant emotions almost twice as often as pleasant ones in their dream data. Then, in a tone strikingly reminiscent of Hall and Van de Castle's, Snyder succinctly summarizes some of the problems encountered when evaluating emotions in dream reports:

On the other hand, Calkins [1893] found it especially difficult to define the prevailing emotions of her reports and attempted to do so in only about 16 percent which were almost entirely unpleasant. Our impression is much more similar to Calkins, since I am particularly unsatisfied with our ability to assess the emotional dimension of our dream descriptions. It did not seem difficult at first, for unwittingly we were frequently inferrring what would have been the appropriate emotion under the circumstances described. Then we began to encounter reports in which the subject emphatically disavowed any such feelings. For instance, a waiter in a restaurant was making erotic advances to the dreamer's sister, resulting in a fist fight; but he specifically denied any accompanying feelings of anger. The fight just seemed like a necessary social amenity. After a few such instances we started all over again, tabulating emotions only when they were definitely identified by the reporter, and none were identified in more than twothirds of the narratives. Even in Group B, where emotions had been the subject of special interest, the incidence was only 35 percent.

Of the emotions which were clearly mentioned, unpleasant categories predominated by a ratio of more than two to one, fear or anxiety being the most common category and anger next. Overall, the affect most frequently mentioned was neither pleasant nor unpleasant, but that of diffuse excitement. (p. 141, my italics) 
Employing a "Process Scoring System" (Corriere, Hart, Karle, Binder, Bold, \& Woldenberg, 1977) to evaluate impacts of "Feeling Therapy" (Hart, Corriere, \& Binder, 1975) on dream diaries, Hartshorn, Corriere, Karle, Switzer, Hart, Gold, and Binder (1977) found:

[Five experienced Feeling Therapy patients] evidenced more feeling intensity in their dreams. In fact none of the patient dreams were rated "no feeling," while every nontherapy $S$ [five undergraduate college students] reported at least one. While expression level was fairly low on the average for the patient group (1.90), it was still much higher than that found among the control group (1.90), who showed almost no expression of feeling whatsoever in their dreams . .

It should be pointed out that we originally expected higher scores on all four process scales for the patient group. We expected more feeling, expression, activity, and clarity in their dreams than we found. (pp. 845-846, my italics)

These data and observations with respect to the frequency of emotions in dream reports, especially for the control group, seem remarkably. consistent with the gist of Hall and Van de Castle's and Snyder's findings.

Jones (1970) has suggested that the "increase in dream recall ability under laboratory [as opposed to home] conditions" (p. 45) may allow the individual investigator to "rule out this tendency toward the prosaic or rule it in, more or less at will" (p. 45) depending on how the dream protocols are collected. In this light, it is worth noting that the studies referred to include instances of both diary and sleep awakening procedures.

The hazards inherent in comparing nonequivalent data are legion, and the focus and structures of these studies are quite different. Nevertheless, two persistent findings emerge: (1) Unprompted dream reports, from both diaries and REM awakenings, exhibit a dearth in 
measured frequencies of apparent emotions; and (2) when emotions are articulated by dreamers, those defined by researchers as "unpleasant" or "negative" predominate over those defined as "pleasant."

If waking and dreaming experiences are essentially "continuous," the implication of these findings for waking experience might prove instructive--if not disconcerting.

\section{DREAMS VENT EMOTIONS}

Conclusions by other authors seem inconsistent with the studies just described. Corriere et al. (1977) and Fisher and Greenberg (1977) see dreams as vehicles for the venting of feelings. Corrier's et al. model maintains that "dreams are pictures of feelings" (p. 807). This position is described as being "in contrast to Freud's analytic theory" (p. 870). Fisher and Greenberg found support for the notion that "one function of dreaming thought appears to be to explore the emotional components of a tension area which may be different from those available to the waking self" (p. 54). Interestingly enough, they report that various research findings are "compatible with Freud's central concept of dreaming, namely, that it offers an outlet or release for internal (unconscious) tension" (p. 62). This assertion is hedged, however, with the usual caveat that it remains to be definitive1y demonstrated.

\section{DREAM EMOTIONS PARALLEL WAKING EMOTIONS}

The studies by Corriere et al. (1977) and Hartshorn et al. (1977) also suggest that some characteristics of dream emotions are consistent with the continuum model of waking versus sleeping mentation framework. 
Corriere et al. report preliminary support for a "parallelism hypothesis, which holds that expression of affect in dreams parallels the expression of affect in waking" (p. 807), but point out that "on1y multidimensional data on both waking and dreaming life can provide a definitive understanding of dream processes" (p. 819). Hartshorn's et al. data were also interpreted to support the parallelism hypothesis, but here again the character of the waking component is only inferential and not systematically evaluated for comparison with sleep reports.

To recapitulate, the studies reviewed so far suggest that (1) emotions in dream reports are infrequent and often unpleasant, (2) dreams are an outlet for emotions, or (3) dream emotions parallel waking emotions. If emotions from dreams and waking experiences were compared, results supporting these three conclusions would seem to cover the entire continuity-discontinuity spectrum.

FOUR RECENT STUDIES: FINDINGS AND METHODOLOGICAL ISSUES

Four studies (Snyder, 1970; Kramer, Winget \& Whitman, 1971; Kroon, 1972; Stairs \& Blick, 1979) afford more specific data about emotions in dream reports. Each incorporates procedural elements which, as with any study, are probably reflected in its findings. Nevertheless, collectively they may serve to summarize more recent findings and highlight certain methodological factors which are relevant.

Snyder (1970) observes that "the feelings expressed in dreams are usually bland and rather nebulous, attracting attention only when they become unpleasant; perhaps that's the way life is" (p. 142). Perhaps? There are two puzzling aspects to this study which Snyder 
describes "as a preliminary reconnaissance of how the state of consciousness described by REM awakening reports compares with waking consciousness" (p. 127). He defines dreaming by

two minimal criteria: first, that the subject's words must clearly convey an experience of complex and organized perceptual imagery. In practice we find that when this criterion is met, the imagery reported is always partially visual. The second criterion is that this imagery must have undergone some temporal progression or change. We didn't accept tableaus, only dramas. (p. 129)

Then, having evaluated 635 laboratory dreams, Snyder concludes that "the broadest generalization I can make about our observations of dreaming consciousness is that it is a remarkably faithful replica of waking life" (p. 133). A "typical dream" involves people in every-day settings doing ordinary things with other people. Snyder describes these findings as consistent with Hall's (1966) and Calkins' (1893).

Now for the two problems: (1) The ultimate findings seem predetermined, to a large degree, by the definition of dreaming; and (2) while dream reports were evaluated in a rigorous fashion, waking experience was determined strictly by the "seat-of-the-pants," if you will. Is it really much of a surprise that when dreaming is defined as "an experience of complex and organized perceptual imagery" dreams involve people in "every-day settings doing ordinary things with other people"? More troublesome, however, is the assertion that this study "compares" REM awakening reports "with waking consciousness" (p. 127) when, in fact, waking consciousness was not empirically assessed. It was purely a matter of subjective opinion. This is evident in the suggestion that "perhaps that's the way life is." In a different context, Snyder properly maintains that "private convictions are of no more 
scientific value than the private dream memories from which they derive" (Kramer, Whitman, Baldridge, \& Ornstein, Eds., 1969, p. 18). This applies to private convictions about waking life as well.

Hall and Van de Castle (1966) and others (Kramer et a1., 1971; Foulkes and Fleisher, 1975; Corriere et al., 1977; Cartwright, 1978) have pointed out that if waking and dreaming experience are to be meaningfully compared, both states must be evaluated, and these evaluations must be as nearly equivalent as possible. The present study attempted to make such a comparison for five classes of emotions.

Kramer et al. (1971) had 300 adults fill out dream survey questionnaires wherein each described his or her "most recent dream and his [or her] earliest memory" (p. 1350). All protocols were evaluated according to Hall and Van de Castle's (1966) scales. They found that both dream and memory reports contained "more negative event outcomes than positive ones, i.e., more failure and misfortune than success and good fortune" (pp. 1351-1352). Sixteen percent of dream reports and 12 percent of early memory reports contained scorable emotions. "Dysphoric emotions were much more common than pleasant ones in both verbal reports" (p. 1352, my italics). Comparing their dream sample to Hall and Van de Castle's (1966) norms, Kramer, et al. state that the "striking feature which emerges is how similar the dream content of the two samples turns out to be" (p. 1353). "Several content differences" were observed, however, when early memory and most recent dream scores were compared. Early memory scores indicated more misfortune to the respondent, fewer with no setting, more castration anxiety and oral incorporation "making them more like what 
Hall and Van de Castle report in their dream content norms" (p. 1353). They conclude that

differences do occur between dream reports and early memories based on an analysis of our data with the Hall and Van de Castle scales, which indicate that different aspects of the respondent's experience are being reflected in the two verbal products. (p. 1353)

When scored according to the Gottschalk-Gleser Verbal Sample Scales (Gottschalk \& Gleser, 1969; Gottschalk, Winget, \& Gleser, 1969) the results indicated

that total anxiety was more frequent than total hostility in both dream reports and early memories and that total anxiety and total hostility were found more often in the dream reports than the early memory. (p. 1353)

When affect was rated as pleasant, unpleasant, and neutral, "dream reports even more than early memories, reflect unpleasant experience" (p. 1354). Kramer et a1. conclude that the "dream report is indeed revealing of different aspects of an individual's inner concerns than other verbal products such as early memories" (p. 1356) and speculate that this difference might reflect the temporal difference between the report and the reported event for the two cases.

Kramer's et al. procedure is a step in the right direction because both waking experience and dream reports were evaluated. The time difference variable for the reported events could be controlled to some degree if subjects were to describe experiences for a given day and dreams from the ensuing night. The present study incorporates such control.

Consonant with this premise, Kroon (1973) had four subjects "record all their recalled dreams as well as their significant interactions while pursuing normal daily activities" (p. 417-B) and 
compared the "longitudinal relationship between affect in response to people in daily interaction and to dream characters" (pp. 416-B-417-B). Each interaction was summarized by the subject and rated on an eight point scale for "seven bi-polar emotional dimensions" (p. 417-B). The overall findings are described as

supporting the idea of continuity of waking and dream experiences over a period of time . . but dream affect was consistently less positive than waking affect, with the greatest wakingdream difference in emotional dimensions measuring hedonic level, followed by those measuring feelings of closeness to other people and self-esteem. Negative feelings tended to emerge only in dreams in the Calm vs. Tense and Close to Other People vs. Alone and Distant from Other People dimensions . . . . Two S's rated more dreams as "pleasant" and two $\underline{S^{\prime} s}$ rated dreams as "unpleasant." (p. 417-B)

This mixed bag might be interpreted in part to confirm the notion of a mostly dysphoric-tone in dream affect. Kroon found that "variations of affect along individual dimensions" (p. 417-B) were not common across subjects, but "were conguent with each S's individual life context" (p. 417-B). Also, correlations suggested "long-term affective continuity in waking and dream experience" ( $p$. 417-B).

Kroon's design incorporates a source of potential bias in requiring subjects to rate emotions. Cohen (1974), referring to numerous studies, contends "that questionnaire and diary measures of dream recall frequency produce results that are closely related and highly predictive of laboratory recall" (p. 139). Nevertheless, in light of Hall and Van de Castle's, Snyder's, and Hartshorn's et al. observations that subjects of ten fail to describe emotions in unprompted dream reports and suggestions that waking and sleeping experiences may or may not be continuous, an important question arises: Are subjects equally reticent to volunteer emotions in 
unprompted reports of waking experience. In order to answer this question, both report formats must be as nearly equivalent and as free from hints regarding the experimenter's interests and expectations as possible. One approach to this end, employed in the present study, might be a night-day report process which is as unstructured and "open-ended" as experimental demands allow. This study attempted to employ such a procedure.

Stairs and Blick (1979) tried "to solve some of the problems that are associated with research involving the emotional content of dreams" (p. 839). Thirteen male and 18 female students recorded five dreams each in dream diaries over a five-week period. "To circumvent the problem concerning the lack of reported emotions" (p. 839), the experimenters presented subjects with "a forced-choice situation in which they had to pick the two strongest emotions that appeared in each dream" (p. 839). The 10 selections offered included nine from Izard (1972) and an "other" class. They found 77 percent of emotions included in the classes of Interest-Excitement, 18 percent; Fear-Terror, 17 percent; Surprise-Startle, 16 percent; Enjoyment-Joy, 15 percent; DistressAnguish, 11 percent, while 23 percent comprised Other, 7 percent; Anger-Rage, 6 percent; Shame-Humiliation, 5 percent; Disgust-Revulsion, 4 percent; and Contempt-Scorn, 1 percent. These data are construed as supporting Snyder's contention that about "one-third of the dreamer's emotions were associated with fear and anxiety" (p. 842).

Stairs and Blick could not directly compare their data with Hall and Van de Castle's (1966) norms because in their study dreamers scored their own dreams and twice as many classes of emotions were used. Nevertheless, in contrast to Hall and Van de Castle, they found "no 
significant differences in dream emotions for men and women" (p. 842). They also question Hall and Van de Castle's contention that "negative emotions of sadness, anger, confusion, and apprehension predominate over the positive emotions of happiness" (p. 842), pointing out that in their data, of the five most frequent emotions ( 77 percent) "only two were unquestionably negative, fear and distress [while] anger, shame, disgust, and contempt each account for 6 percent or less of all dream emotions" (p. 842). Concluding this line of reasoning, Stairs and Blick reach "a guarded conclusion . . that maybe dreams have more positive emotions than had previously been thought" (p. 842).

Conclusions drawn from comparisons between studies, and indeed within a given study are, of course, critically determined by respective definitions of variables and by how the resultant data are conceptualized. For example, one might subjectively categorize Stairs and Blick's data as (1) affectively positive: Interest-Excitement, 18 percent; Enjoyment-Joy, 15 percent, (2) affective1y neutral: Surprise-Startle, 16 percent; other, 7 percent, and (3) affectively negative: Fear-Terror, 17 percent; Distress-Anguish, 11 percent; Anger-Rage, 6 percent; Shame-Humiliation, 5 percent; Disgust-Revulsion, 4 percent; Contempt-Scorn, 1 percent. Grouped in this fashion, the overall proportions become: positive, 33 percent; neutral, 23 percent; negative 44 percent. These data may be seen as more consistent with findings which conclude dream emotions are more negative than positive. There are, of course, countless variations on this theme making speculation just that. This does not, of course, detract from the merit of the study. 
It is worth noting that, like Snyder, Stairs and Blick did not measure waking mentation; but unlike Snyder, they never professed to. If one of the problems which they set out to solve was an apparent "lack of reported emotions". in dream reports, they may have failed. Circumvention goes around a problem. It can provide important findings, but the circumvented problem may remain.

To summarize from the four preceding studies, three describe dream emotions as predominantly negative, unpleasant, or less positive than emotions from waking experience. This is consistent with the findings noted earlier. Stairs and Blick alone make a "guarded conclusion" that dreams may be more affectively positive than formerly thought. The two studies which did not focus subject's attention on the dependent variable found a paucity of emotions in dream reports. A1l except Stairs and Blick, who did not address the issue, report some degree of overall support for the notion of continuity between waking and dreaming experience. However, the two studies (Kramer et al., 1971; Kroon, 1973) which actually measured and compared emotions from both waking and dream reports found that dream reports exhibit more total anxiety, total hostility, and unpleasant experiences, and were consistently less positive in affect than waking reports. In an observation reminiscent of Vogel's (1978) independent processes model, and surprisingly similar to Fisher and Greenberg's (1977) suggestion, Kramer et al. go so far as to state that their data "indicate that different aspects of the respondent's experience are being reflected in the two verbal products" (p. 1353). 
These various results suggest that emotions in dream reports may indeed be, if not discontinuous, at least different from emotions in reports of waking experience. At the same time, manifest dream reports seem to exhibit a structural continuity with reports of waking experience which is consistent with idiographic personality variables. In other words, the relationship between the two states is probably not of the Jekyl1-Hyde variety. Within this framework, however, there is extensive evidence that emotions from dream reports are more unpleasant than emotions from reports of waking experience.

Certain procedural factors seem critical to a proper comparison of waking and dream reports: (1) Reports of experiences from both the waking and dreaming states must be secured under conditions as nearly equivalent as possible. (2) Report formats should be identical and derived from a relatively brief, contiguous time frame. (3) Subjects must have a minimum of prompts regarding the primary dependent variables, i.e., emotions. (4) All reports should be randomly assembled and rated using the same instrument. (5) Raters must have as few clues as possible regarding the independent variable state, i.e., waking or dreaming, reflected in any report, and (6) interrater reliability must be assessed. While the four studies just considered may afford valid data and useful findings, none fulfills all of these criteria. This project, while incorporating its own flaws, attempted to honor these requirements. 
CHAPTER IV

EMOTIONS IN DREAIS

THEORIES OF EMOTIONS

What are emotions anyway? This question has been consistently ignored by researchers and theorists interested in dream emotions. Plutchik (1970) describes "three major traditions concerned with the nature of emotions" (p. 3). The evolutionary or Darwinian model sees "emotional expression in lower aninals and in man" (p. 3) as continuous. This model emphasizes the "expressive and behavioral aspects of emotion" (p. 4). William James' position that "bodily changes follow directly the perception of the exciting fact, our feelings of the same changes as they occur is the emotion" (James \& Lange, 1922, p. 11) was discounted by Cannon (1929) because certain known "visceral" characteristics are incompatible with the model (see Schachter in Arnold, Ed., 1970, p. 115). The third major tradition in emotional theory which Plutchik refers to is the Freudian model wherein "'archaic discharge syndromes' . . are part of the biological inheritance of man" (p. 4).

Plutchik also describes "cognitive aspects" of emotion wherein an organism evaluates "its environment" (Arnold, 1960). Plutchik maintains "that an evaluation of a perception is not an emotion. Evaluations are only part of a total process which involves an organism interacting with its environment in biologically adaptive ways" (p. 9). Arnold's (1969) 
analysis and definition of emotion, which will be reviewed presently, is much broader than this critique implies. Arnold describes emotion not as "an evaluation of a perception" but as a "felt tendency" to act which is integral to the perception-appraisal-action complex, but this is getting ahead of the story.

[Plutchik defines] an emotion as a patterned bodily reaction of either protection, destruction, reproduction, deprivation, incorporation, rejection, exploration or orientation, or some combination of these, which is brought about by a stimulus. (p. 12)

Based on this definition, one might wonder about the nature of dream emotions if bodily reactions require voluntary components and stimuli are extrinsic to the dreamer. Some implications from these premises will be explored presently.

Arnold's (1960) evaluation of Emotion and Personality is relevant to a consideration of dream emotions. In Volume I: Psychological Aspects, subjective impression and empirical findings are carefully synthesized in a description and concise definition (p. 182) of emotion. Volume II recounts the Neurological and Physiological Aspects which predicate Volume $I$.

Arnold's discussion of Freud's thoughts about emotions is instructive. She maintains that Freud's primary interest was not in emotions per se but in "personality and its disturbances" (p. 133). In this context, however, he "found that emotional difficulties . . played a far greater role than purposive activity" (p. 133). Before 1900 Freud held that the instincts of love and aggression carried "an 'affective charge' which is the psychic counterpart of instinctual energy" ( $p .136)$. The discharge of this energy "is experienced as 
emotion or affect (discharge theory of affect)" (p. 136). One problem with this position was that "no pleasure should be experienced until the instinctual aim is reached" (p. 136). Recognizing this, Freud's followers "suggested that emotions represent increasing or decreasing excitation rather than sheer discharge of the drive" (p. 136). After about 1900 Freud saw "emotion as the experience of autonomic excitation induced by ideas in the unconscious" (p. 136). The pleasure principle discharged "instinctual tension" via the autonomic system and the reality principle discharged them via the motor system (p. 136). Affect then

acts as a safety valve when tension is too high and action is delayed. But [Arnold points out] if emotion is an alternative to action, and action is not possible at all [as in dreams], the emotion felt is frustrated love, impotent anger, or helpless fear, none of which is pleasant. (pp. 136-137, my italics)

This observation is intriguing in light of the previously discussed findings regarding dysphoric emotions in dream reports. Arnold believes that Freud's discharge and safety valve models together do not explain "the displeasure of frustration" (p. 137) or emotions like joy or sorrow where there "is no urge to action, hence no instinctual energy cathecting an object" (p. 137). It also bothers her that Freud saw anxiety not as an "affect charge" but as an emotion reflecting frustrated drive discharge and thus as a special case.

Arnold finds Freud's propositions about emotions untenable at two points. First, she questions the premise of emotions as instinctually based. Referring to the endocrine system, she points out that instinctual forces are not constant but periodic and precede perception. In practice "the somatic state comes before [and sensitizes] 
perception and appraisal of an object in instincts [hunger, sex], but after such appraisal in emotions" (p. 142). Arnold's second disagreement with Freud concerns the apparently different genesis of different emotions.

Though anxiety (fear) was still thought to be aroused by the perception of a threat, love and anger become the affect charges of the libidinal and aggressive drives. As such, they are aroused by an object, but are experienced when the drive cathects the object. Whatever the merits of this explanation for personality theory, for a theory of emotion it is unacceptable because it makes an unjustifiable distinction between emotions aroused by objects and emotions that are the experience of a drive cathexis. ( $p .170$ )

Arnold maintains that "Freud himself never felt quite easy over this division" (p. 139).

While Arnold's own theory of emotion is referred to as "cognitive" (Arnold, Ed., 1970), it is extensively grounded in physiological

research and accounts for psychological and behavioral components. She asserts that any "definition that really attempts to define always includes the experience as well as the motor aspect of emotion" (p. 92), that psychologists have always agreed on this point, and that they "have disagreed only in what they consider cause and what effect" (p. 93).

Arnold then proceeds to "discover" how the felt experience and physical upset are related and "how such an all-over effect can arise" (p. 92). She maintains that "the explanation of the mechanism producing this all-over effect is crucial for any theory" (p. 93) and postulates cognition to fulfilling this function. In the end, Arnold describes emotion as

the felt tendency toward anything intuitively appraised as good (beneficial), or away from anything intuitively appraised as bad (harmful). This attraction or aversion is accompanied by a pattern of physiological changes organized toward approach 
or withdrawa1. The patterns differ for different emotions. (p. 182)

This is described by Arnold as a "perception-appraisal-emotion" (p. 177) mode1. It stands in contrast to descriptions of emotion which "telescope perceiving and doing into one action sequence" (p. 178) and, as Arnold sees it, fail to "explain why the same perception results sometimes in one and sometimes in another emotion and action" (p. 178). Arnold's paradigm comprises four aspects: perception, intuitive appraisal, felt tendency (the emotion proper), and physiological change organized toward action. The key element is appraisal:

at the base of every emotion there is some kind of perception or awareness of an object, a person, or a situation, which in some cases becomes emotional, in other cases remains (in the words of William James) a 'cold perception.' (p. 93)

The object of perception may be present or "merely imagined" (p. 171). To perceive is to recognize an object, person, or situation as it exists apart from its effect on me. Objects, persons, or situations may be perceived without engendering emotion.

Appraisal which is "direct, immediate, intuitive" (p. 172) completes perception. Perceptions inhering emotions require a subjective element which is appraisal. It is a non-reflective "sense judgment of weal or woe" (p. 172) for me personally. In emotion "the object must be appraised as affecting me in some way, affecting me personally as an individual with my particular experience and my particular aims" (p. 171). Arnold claims a "psychological capacity of appraising" (p. 173) which is innate but not infallible. She reasons that this capacity is not a function of learning because without memory 
and appraisal learning from past experience seems impossible to begin with.

[Intuitive appraisal] is often supplemented or corrected by later reflections. When this happens, the emotion changes with the new intuitive estimate which follows the corrective judgment . . . Whenever there is no intuitive appraisal . . but only reflective judgment, the matter becomes strictly speculative--there is no emotion. This seems to happen in the emotional flattening of the schizophrenic. (pp. 175-176)

Whatever its merit, this comment is interesting in light of the observed qualities of dream emotions which might be described as more emotionally "flat" than waking emotion. In a similar vein, Arnold holds that if emotions seem

vague and objectless, as in neurotic anxiety or in depression [or dreams?] . . . These are departures from normal functioning. Normal emotion carries with it the reference to an object or situation that is known in some way. (p. 170)

All perceptions and appraisals do not lead to emotion. For Arnold, the third requisite of emotion is a felt action tendency which derives from perception and an intuitive appraisal that an object, person, or situation is either desirable or threatening. This felt tendency is "expressed as various bodily changes, and . . . eventually may lead to overt action" (p. 177). Arnold regards "feeling [as] a direct experience and neither a construct nor an inference" (p. 70) and suggests that "the emotional quale consist precisely in that unreasoning involuntary attraction or repulsion" (p. 172). Merely recognizing a thing or person or knowing that it is "theoretically or abstractly" good or bad for me does not trigger emotion.

But if I think something is good for me here and now, and feel myself drawn toward it sometimes even against my better judgment, then my experience is properly speaking, nonrational; it is other than just cold reason; it is an addition to knowledge: it is emotional. (p. 172) 
A felt tendency of attraction or repulsion is "an impulse to action that brings with it a host of physiological changes" (p. 178). These changes constitute the fourth element in Arnold's paradigm. They demand action under penalty of distress. "To act as we feel urged to act, so that we finally reach the goal we desire, brings not only the possession of what we long for but also alleviates physical discomfort" (p. 179). Arnold notes that physical upset follows perception-appraisalfelt tendency, citing research findings that "emotion is reported before any peripheral changes can be felt or observed" (pp. 179-180). Ten years after its definitive inception Arnold's description of the emotional process was essentially intact.

The emotion becomes a felt tendency toward anything appraised as good, and away from anything appraised as bad. This definition allows us to specify how emotion is related to action. It also allows us to state how emotion is aroused: whatever is perceived, remembered, imagined will be appraised; if it is appraised as desirable or harmful, an action tendency is aroused. And as we appraise the situation as more desirable or harmful, we become aware not only that we tend toward or away from it, but also that this is an emotional tendency. (Arnold, Ed., 1970, p. 176)

Here the function of subsequent appraisal is apparent. Moreover, Arnold (1970) maintains that "most of the newer theories [see Arnold, Ed., 1970, Part III] of feeling and emotion assume that these experiences depend on the interpretation and evaluation of the situation" (p. 123). Differences in the various models hinge on definitions of cognition and "the relation of emotion to action" (p. 124).

\section{EMOTIONS AND SLEEP PHYSIOLOGY}

The joint event comprised by concomitant emotion and sleep physiology is a critical juncture in conceptualizing dream emotions. 
This perspective, too, has been neglected by dream researchers and theorists. This section considers some theoretical aspects of emotions within certain physical constraints of sleep and proposes some explanations for findings of few and dysphoric emotions in dream reports. Arnold's paradigm for emotion is referred to because it lends itself to the purpose. Other models might serve as we1l. The psychoanalytic viewpoint, for example, would seem to afford an especially intriguing perspective from which to examine concomitant emotional and dreaming states.

To recapitulate, Arnold describes emotion as follows: (1) An object, person, or situation is perceived or imagined, (2) immediate, intuitive appraisal occurs, (3) a felt action tendency toward or away is experienced as emotion, (4) physiological changes occur organized toward approach or withdrawal, and (5) overt action may ensue. Now to look at each of these aspects of the emotion process during sleep. For Arnold emotion requires perception which may either involve sensory experience or be imagined. Arkin and Antrobus (in Arkin et al., 1978, pp. 352-366) reviewed studies of the impact of external sensory stimuli during sleep. They conclude that "cognitive responses of some form may occur in both REM and NREM sleep as a result of external stimulation" (p. 366); and when such responses are noted, the stimuli are often transformed or only partly represented. In sleep, responses to stimuli originating outside the sleeping person probably occur much less often than not, and perception is more of the imagined variety. While Arnold points out that imagining may get us just as "stirred up" as experience, it is still plausible that limited perceptual data could 
impact on dream emotions. A characterization for this impact will be suggested after appraisal, which "completes perception," is discussed.

The appraisal element of emotion may or may not operate in dreams as in waking experience. If it proceeds "normally," we instictively judge perceived or imagined events or people as good or bad for us personally--so far so good. If, however, this mechanism operates differently or does not operate during sleep, various scenarios might ensue. Arnold maintains that where no appraisal and only reflective judgment occurs "there is no emotion" (p. 176). One explanation for a scarcity of emotions in dream reports is that intuitive appraisal, and hence emotion, occurs less frequently or differently in dreams than in waking experience.

An absence of appraisal and a predominance of reflective judgment could derive from the fact that a dream report is a recounting and not a dream. A critical and obvious issue, but one easily overlooked, is that second parties never observe dreams. Snyder's (1969) summary of this matter is concise.

As many have pointed out before, the only relevant empirical data ever available to us are reports of dream memories, prodducts of the waking mind, reflecting all of its complexity and fallibility. So our raw data are already twice removed from hypothetical origins: first by the wrenching transition from sleeping or dreaming to waking, and secondly by the perilous translation from subjective experience to verbal reports. But, even in this form, such reports are merely collections of words; usually, in order to make any use of them, we then subject them to an additional process of judgment, analysis or other variety of manipulation. Surely if there were any alternative approach to this matter, we would recoil from such dubious, third-hand information--but there is not. (p. 18)

These issues are especially relevant with regard to emotions in dreams when considered from Arnold's perspective where emotions are by 
definition intrinsic with experience. If emotions in my dream report seem inappropriate or "curiously lacking" to a naive observer, this could be because that observer did not experience the dream. My dream is exclusively my creation. I wrote the script. Before the onset, I knew the score. No one else may know it as I do. To the degree that a report is reflective, emotions are recounted and not reexperienced. For a second party they may only be inferred from verbal identification or described dream behavior or circumstances. True emotions in dream reports are waking and not dreaming emotions. It would seem that actual emotions may not transpire in written accounts.

Findings of predominantly dysphoric emotions in dreams might be accounted for at the perception-appraisal stage. In this case appraisal would seem to harbinger negative consequences for the dreamer. Why? A clue may be found in the studies previously cited. Emotions described as negative, dysphoric, or unpleasant are defined differently by different authors. Snyder found that "the affect most frequently mentioned was neither pleasant nor unpleasant, but that of diffuse excitement" (p. 141). Fear and anxiety, however, constituted one-third of dream emotions in Snyder's study. Stairs and Blick agree with Snyder in this regard. Kramer et al. found negative event outcomes, anxiety, and hostility more frequent in dream reports than early memory reports. Kroon observed that subjects felt more often tense and distant from other people in dreams than in daytime reports. In Hall and Van de Castle's norms, confusion and apprehension constitute over one-half of the total dream emotions for both men and women; for the dreamer as a character in his or her dream, essentially one-half of emotions fall in these two 
groupings. Hall and Van de Castle's classification of "apprehension" includes "fear, anxiety, guilt, and embarrassment" (p. 111). They concede that "confusion" is probably not an emotion noting that it "resides more in the head as a state of cognitive ambiguity than it does in the viscera as a gut-type reaction" (p. 112, my italics). One might wonder about this observation in light of Arnold's model. In summary, these various researchers define dysphoric emotions as feelings like fear, confusion, ambiguity, and tension while anxiety crops up everywhere.

A brief example might illustrate a possible link between restricted perceptual data, appraisal, and these kinds of dysphoric emotions. When something leaps from the bushes, I react instantly; and I look to the object or the situation for clues. Is it a monster!? While the data are ambiguous or scarce, I am anxious; confused, apprehensive, tense, and fearful. When $I$ believe that $I$ have the correct information from the environment, I fight, run, or laugh in comic relief: It's a halloween costume! Between initial perception and ultimate action, I rapidly reappraise the information available from the environment.

Arnold's idea of serial appraisals based in perception is consistent with other authors. Schachter and Singer (1962) cite Plutchik (1938); Hunt, Cole, and Reis (1958); and Schachter (1959) to suggest "that one labels, interprets, and identifies this stirred-up (emotional) state in terms of the characteristics of the precipitating situation and one's apperceptive mass" (pp. 379-380). Cognition "exerts a steering function" (p. 380) in the present situation based on past experience. Schachter and Singer interpret their findings to support this contention. Their 
study and paradigm are subject to question on both methodological and theoretical grounds (Plutchik, 1970, p. 7); nevertheless, a salient role for external data in the cognitive evaluational aspect of emotion seems reasonable. If we often depend on external data to identify emotions and if, as previously noted, access to these data is restricted if not precluded during sleep, then emotions reflecting anxiety, confusion, tension, or fear might well prevail.

Arnold's third and fourth aspects of emotion, a felt tendency to act--the emotion proper--and physiological change organized toward approach or withdrawal, must in dreams conform with the physiology of sleep. A comprehensive discussion of sleep physiology is far beyond my expertise and the scope of this presentation, but a brief review of same salient points may suffice. To this end, Pivik's review of "Psychophysiological Models of Sleep Mentation" (pp. 245-271) in Arkin et al. (1978) is instructive.

According to Pivik, the conceptualization of sleep has progressed through three phases. Historically, sleep was seen as unitary. In 1953 Aserinsky and Kleitman observed periods of "eye motility," and quiescence during sleep and ushered in the now familiar REM (rapid-eye-movement) and NREM (non-rapid-eye-movement) (Dement \& Kleitman, 1957) or two-state mode1. Aserinsky and Kleitman obtained dream reports from REM awakenings 74 percent of the time. Snyder (1969) notes that "at least sixteen systematic studies" (p. 18) have essentially replicated these findings. Moruzzi (1963, 1965) proposed the most recent sleep paradigm. According to Pivik, this "tonic-phasic" model sees REM sleep as including "irregular alteration between periods of 
of activity upon which are superimposed 'sudden [erruptions] of an ensemble of phasic events [Moruzzi, 1963, p. 291-292]'" (p. 253). Differences in tonic events, REM-NREM, were described as "largely ones of degree and not of kind . . [while] phasic events within REM represented activity which was fundamentally different from the tonic background upon which it was superimposed" (p. 254). To skip a lot of interesting findings and reasoning and summarize very briefly, Pivik maintains that the two-state REM-NREM dichotomy has "been laid to rest (Dement, 1973)" (p. 268) as an heuristically viable model and concludes that attempts to match temporally discreet physiological and psychological measures during sleep have failed. In a forward to Pivik's presentations, S. J. Ellman (Arkin et a1., 1978) observes "the hope that physiological conditions will be translated directly into mental events" (p. 244) is belied by "the history of sleep research" (p. 244). While "it is clear. - that phasic activity is not the determinant of sleep mentation per se" (p. 268), ultimate implications from the tonic-phasic paradigm are less clear.

While phasic activity may not determine sleep mentation, its components are interesting with respect to dream emotions. This cyclic temporal clustering of certain activities, Moruzzi's "ensemble," is recognized by most researchers (Pivik, p. 246). In his review of "The Physiology of Dreaming" (Kramer, Ed., 1969, pp. 7-31), Snyder notes that the state has been called by almost two dozen names with "REM" probably the most familiar. Jones (1970) lists some of its elements: concomitant presence of irregular pulse, blood pressure, and respiration; penile erection; rapid conjugate eye movement; sporadic activity of certain fine muscle groups; near absence of tonic anti-gravity muscle potential; a low voltage 
desynchronized cortical EEG pattern; high brain temperature and metabolic rate; and, in humans, a high-positive correlation with ability to report dreams upon being awakened. (pp. 24-25)

As preface to further consideration of Arnold's model of emotion during sleep, one might combine these scientific findings with a homely observation: During sleep our capacities to see, hear, smell, touch, and taste are quite restricted and purposeful voluntary motor activity such as walking, talking, and using our hands is rarely exhibited. At the same time, there transpire periods of involuntary physiological arousal, the origin and function of which are presently not understood (Snyder, 1969). This combined state could reflect tendencies to act and attempts at physiological change organized toward action, Arnold's third and fourth components of emotion, where things are "stirred-up" autonomically, but may not achieve operant fruition because in dreams voluntary motor behavior is essentially paralyzed! Perhaps the roots of dysphoric dream emotions like tension, apprehension, or anxiety lie here.

All things considered, it would not be surprising to find emotions stylized by at least two constraints of sleep physiology: (1) most perceptions are limited to intrinsic referents, and (2) voluntary motor capacities are effectively precluded. These constraints could impact throughout the emotion process. Since perception and appraisal which completes it probably of ten depend on extrinsic information, emotions experienced when these data are excluded might reasonably reflect anxiety and confusion. Felt tendencies to act and concomitant physiological adaptation organized toward action may develop to a degree consistent with the respective perception and appraisal; however, since access to voluntary motor behavior is very limited in sleep and 
particularly so during periods of more prolific dream recall, overt action may not ensue. Within the sleep framework, when imagination engenders emotion, the net affect could be reflected in periods of autonomic arousal which are recounted after waking as tension, confusion, and apprehension.

At another leve1, since the dream is totally the dreamer's creation and nothing is ever a surprise,

situations that would undoubtedly be terrifying or depressing for the average individual [under awake conditions] may be reported in some detail, but [with] a description of their emotional impact upon the dreamer . . . curiously lacking (Hall \& Van de Castle, 1966, p. 110)

from the standpoint of the nondreaming observer who does not know the score. 


\section{CHAPTER V}

\section{METHODOLOGY OF DREAM RESEARCH}

While the potential list may be interminable, Winget and Kramer (1979) list seven "factors which separately and in interaction may influence the content of the verbal report obtained" (p.6). These are: (1) the setting, (2) the method of awakening, (3) the interpersonal situation between the dream reporter and the dream collector, (4) different stages of sleep and times of night, (5) the method of recording the dream report, and (6) the type of subject from whom the dream is collected. These and related elements will now be considered under headings of subject and procedural factors.

\section{SUBJECT FACTORS}

The role of idiographic or personality factors in the expression of emotions in waking and dream reports has been investigated (Starker, 1973, 1974, 1977; Cohen, 1974; Fisher \& Greenberg, 1977). Following a train of research, Foulkes and Rechtschaffen (1964); Foulkes, Spear, and Symonds (1966); Vogle, Foulkes, and Trosman (1966); and Vogel (1978) compared waking, hypnagogic or sleep onset (SO), and REM fantasy in various contexts. Foulkes et al. contend that the hypnagogic nondreamer exhibits characteristics of the

'authoritarian personality' syndrome ... [ and] exerts rigidly successful control over his impulse life, [while] the high nocturnal fantasizer shows fascination with impulse life . . in conjunction with weakened ego control mechanisms. (pp. 284-285) 
With respect to emotions specifically, a decline in affect "concomitant with an increase in hallucinatory dreamlike experience" ( $p$ 235) was noted with "emotional flattening [being] the primary affective characteristic of the hypnagogic period" (p. 235). Vogel (1978) defined "four SO EEG/EOG stages . . ranging in succession from awake and alert, or awake but drowsy, through drifting off to sleep, to light sleep" (p. 97). In general "a steady decline in control over the course of mental activity and awareness of the immediate environment and a steady rise in the frequency of hallucinatory experience" ( $p$. 98) accompanied this sequence; however, large variations in this scheme reflecting individual differences were noted. The overall essence of these studies may be expressed in Vogel's conclusion that "the central empirical findings . . . are:

(1) that SO and REM fantasy are independent of each other; and (2) that each is related to different waking personality variables" (p. 107). so fantasy is seen as initiated voluntarily through ego regression and is related to waking fantasy, whereas REM fantasy stems from unconscious wishes and is "never volitionally initiated" (p. 108). Edney (1980) points out that this is a psychoanalytic explanation and supports the independent processes mode1.

Starker (1977) examined "the relationship between patterns of daydream activity and nocturnal dreams" (p. 411) for three individual "'styles' of daydreaming . . (Singer \& Antrobus, 1963, 1972; Starker, 1973; Isaacs, 1975)" (p. 411). These are the Guilty-Dysphoric, Positive-Vivid, and Anxious-Distractible styles. He concluded that

when persons of differing but relatively pure daydream styles are compared as to nocturnal dream characteristics, the stylistic consistencies observed in waking fantasy appear also in dream productions, particularly affective polarity and 
bizarreness. Dreams and daydreams appear to be highly interrelated aspects of the fantasy process, sharing important affective and structural components. (p. 411)

Vogel (1978) and Starker (1977) represent different but, in certain respects, similar lines of research and thought. Both identify personality structures which are consistently reflected in both waking and sleeping fantasy productions. Within a given structural pattern, Vogel sees independent functions for the two fantasy states, while Starker points to marked degrees of consistency between them. Maybe these positions are not incompatible: While overall, idiographic styles of thinking, reflected in fantasies, remain generally constant across waking and sleeping experiences, the functions of the respective fantasies serve different purposes or are, at least, expressed differently. Most salient to the present purpose, both lines of thought and research identify patterns of mentation with significant affective components. These patterns characterize relatively distinct personality groups and are evident in both waking behavior and dream reports. There is good evidence that dream reports from so-called "recaller" and "nonrecaller" populations differ not only in quantitative but qualitative dimensions, and these differences persist without regard to the report setting. Lewis, Goodenough, Shapiro, and Sleser (1966) found that even when subjects sleep in a laboratory, while "nonreporters and reporters did not differ in REM-period frequency or EEG patterns during sleep, non-reporters did report dreams less frequently following REM-period awakenings" (p. 52). While quantitative report differences define the two populations, Barber (1969) found that dream "Reporter reports were easier to recall and contained more drive content than Nonreporter reports. There were no differences in recall ability" 
(p. 248). Cohen (1974), too, concluded that individual differences in memory do not account for differences in dream-recall frequency (p. 142), and suggested that "factors peculiar to the dream itself and to the sleep and waking situation need to be explored" (p. 142). Cohen and MacNeilage (1973) examined REM reports from recallers and nonrecallers across "four salience dimensions" and found recallers' dreams to be more vivid and bizarre while incoporating more affect and activity by the dreamer.

Hall and Van de Castle (1966) confirmed a typical finding that females' dreams are about 8 percent longer than males'. Their female subjects reported more total emotions in dreams than did male subjects. Since female reports were longer, this difference may be a function of report length.

\section{PROCEDURAL FACTORS}

A body of studies exists to indicate that the introduction of emotionally loaded factors before sleep may influence emotions in dream reports (Foulkes \& Rechtschaffen, 1964; Goodenough et al., 1975; Torda, 1975; Lehto, 1980). Foulkes and Rechtschaffen found that violent TV westerns preceded REM reports which were "longer, more imaginative, more vivid" (p. 996), but not necessarily "more emotional" than reports following nonviolent TV westerns. Using a multifaceted design wherein subjects viewed "stress films" before sleep, Goodenough et al. concluded that "at least under the conditions of this experiment it seems clear that a stressful event during the day can produce anxiety dreams" (p. 317). Torda examined reports from REM awakenings to suggest that endogenous affects [induced by posthypnotic suggestion or anxiety inducing pre-sleep films] may modify the content of concurrent dreams. These concurrent 
emotions become incorporated into the memory traces of the dream. (p. 258)

Lehto (1980) found that when subjects were assigned topics to dream about, those who were operationally defined as controlling dreams about unpleasant topics "had significantly lower amounts of REM activity . • [and] significantly lower \% REM time" (p. 3) than did subjects contro1ling pleasant dream topics. While these studies suggest that emotional components of waking experience may influence subsequent dream reports, the precise extent and quality of these effects are unclear.

The issue of whether "home" or laboratory dream reports are a more valid and reliable measure of the dream experience has an interesting history which is intimately involved with assumptions about the nature of sleep and related procedural matters. When sleep was viewed as an unitary experience, dreams were recalled spontaneously after awakening and seemed too subjective to manage within the traditional scientific paradigm. The discovery of REM sleep spurred the hope of a physically defined parameter of dreaming and triggered an onslaught of laboratory sleep studies in which subjects were awakened during a predetermined physiological state. But as early as 1959 Goodenough, Shapiro, Holden, and Steinschriber suggested that occular activity alone is not the key to dream recall. They found individuals differ in frequencies of dream recall and that these differences maintain even for REM awakenings. Also, a "surprisingly high percentage of recall" (p. 297) was found from periods of occular quiescence. In 1962 Foulkes suggested that "reportable mental activity is always present in the sleeping human" (p. 24). Hall and Van de Castle (1966) found evidence to indicate that reports from REM awakenings and those recalled after 
arising in the morning "do not differ in any important respect" (p. 32). Cartwright (1969) reported "increasing evidence of dreaming having an independent existence outside of REM time" (p. 366) and, reflective of Foulkes, that mental activity appears to be continuous throughout the twenty-four hour day" (p. 369). By 1978 Goodenough was able to cite numerous evidence and studies to indicate "that the REM definition of dreaming is inadequate" (p. 115).

Nevertheless, researchers observed apparent differences when they compared reports of spontaneously recalled dreams with dreams reported after laboratory awakenings. Hall and Van de Castle (1966) and Weisz and Foulkes (1970) contended that while "impulse-related content" (Weisz \& Foulkes, p. 588) such as "aggression" (Hall \& Van de Castle, p. 32; Weisz \& Foulkes, p. 588) is more prevalent in home dreams recalled after awakening than in laboratory reports, the two "do not differ in any important respects" (Hall \& Van de Castle, p. 32). Cartwright and Kaszniak (1978) concluded that laboratory dreams are "less dramatic than those dreamed at home" (p. 277).

Cohen (1969 b) found that dreams remembered in the morning, which usually seem more dramatic, are often from early or late REM periods while the "longest and most intense dreams [come from] nights with fewer REM periods" (p. 435). He also pointed to individual differences, noting that remembered dreams are more frequent "for subjects with greater density [more eye movements per REM period] and lower awakening reaction time" (p. 435). At the same time, Cohen noted growing interest associated with different stages of sleep under varying experimental conditions (Foulkes, 1966, 1967; Goodenough, 1967; Goodenough et al., 1965; Lewis, Goodenough, Shapiro, and Sleser, 1966). (p. 434) 
They suggest that the dream experience might be profitably investigated using either the home or laboratory format.

Cartwright and Kaszniak (1978) reviewed "The Social Psychology of Dream Reporting" (Arkin et al., Chapter 8). They describe the laboratory and home settings as sleeping "in public or in private" (p. 278) respectively and conclude that a report reflects the situation as it is "valued by the subject" (p. 291). Laboratory reports "tend to support one's waking motivations and enhance a sense of self-worth in that context" (p. 291). Presumably a subject's evaluation of the report context whether it be home or laboratory will impact on the dream report. On the other hand, Weisz and Foulkes (1970)

concluded that, although impulse-related content may be more likely to occur in home dreams than in laboratory dreams, the basic dream processes of imagination, distortion, dramtization, etc., are the same in both settings. (p. 588)

Rather than debate which is better, Cartwright and Kaszniak suggest that

dreams collected in the laboratory be understood as behavior in their own right, not as pale shadows of the more 'real' home dreams. All dreams have both state and trait characteristics and as such must be interpreted in the light of the particular emotional context which preceded them and the motivation operating at the time. (p. 291)

A comparison of either home or laboratory reports with verbal reports of temporally preceding waking experience evaluated in a similar fashion might afford clues to the concomitant emotional and motivational parameters alluded to by Cartwright and Kaszniak as well as other variables of interest. This study might be described as a comparison of emotions from dream reports with "the particular emotional context which preceded them." 
Since a home diary report procedure was used, reference to Domhoff (1969) and Cohen (1974), who prefer home reports, is pertinent. Consistent with others, Domhoff found that home dreams exhibited greater proportion of aggression, sexual interaction, misfortune, and castration anxiety, and more aggression, friendliness, sex, success, failure, and both good and bad fortune than did laboratory dreams. He emphasized "psychological vigilance in the laboratory rather than selective recall" (p. 214) to explain the more colorful nature of home dream reports. Domhoff feels that home reports are a more representative sample of dream experience than reports from REM awakenings and tap "deeper layers of the human psyche" (p. 215). Some would, of course, contest this assertion. The point is that home dreams may afford acceptable data, idiosyncrasies notwithstanding.

According to Cohen (1974):

dream recall and dream-recall frequency are assessed by questionnaire, diary, and sleep interruption methods. Earlier reports (Cohen, 1969 a) suggested that such measures are not always closely related. However, more recent data indicated that the close relationship among them justifies the assumption that results obtained from the use of any one of the approaches can be generalized. For example it has been found repeatedly and reported in published (Cohen, 1972 a; Cohen, 1973 b; Cohen \& MacNeilage, 1973; MacNeilage, Cohen, \& MacNeilage, 1972) and unpublished studies that questionnaire and diary measures of dream-recall frequency produce results that are closely related and highly predictive of laboratory recall (Cohen \& MacNeilage, 1973; Lewis, Goodenough, Shapiro, \& Sleser, 1966). (p. 139)

Cohen believes that constructs such as repression, salience, and interference address the issue of dream recall while dream recall frequency is a function of "life style (personality)" or "individual differences" (p. 138). He contends that "salience" and not repression 
critically determines dream recall; and if this be so, "a sample of available reports is a psychodynamically unbiased estimate of the population of dream experiences" (p. 150) wherein the "editorial activities" of the reporter enhance the individual character of the report.

Both home and laboratory procedures influence data. The setting; the interpersonal relationship between the dream reporter and the dream collector, especially as it is interpreted by the reporter; the personality of the report; and the manner in which reports are secured all interact in complex ways to characterize dream reports. No method is "best," but one may better suit specific research objectives. Sampson (1969) suggests that both home and laboratory procedures influence results. "The relevant sampling issue . . is not (in my opinion) whether home dream reports are in some sense biased [but, rather, are they] useful and reliable" (p. 221-222) for the purpose at hand. Of course, results must be viewed in the light of procedures. Different methods may generate data which are valid in portraying different aspects of a highly intricate dream, dream-recall, dream report conglomerate.

Hall and Van de Castle (1966) and others (Kramer et al., 1971; Foulkes \& Fleisher, 1975; Corriere et al., 1977; Cartwright, 1978) contend that questions which involve meaningful comparisons of an individual's dreams and waking life "are best answered by having reliable measures of dream behavior and waking life behavior" (p. 25). For these comparisons to exhibit at least face validity, all reports must 
derive from procedures which, while surely not identical, attempt a semblance of equivalence.

In the present study, the key question is: How do emotions in dream reports compare with emotions in reports of waking experience? The critical design elements are not peculiarities of particular sample group or procedure, but rather that both dream and waking experience reports are obtained from the same subjects under circumstances which are as nearly equivalent as possible within practical limitations and that reports are evaluated according to identical criteria. Since prior comparisons of this sort have either not really measured waking experience (Snyder, 1970; Stairs \& Blick, 1972), measured waking and dream reports of events from two very distant points in time (Kramer et al., 1971), or forced subjects to report affect (Kramer et al., 1971; Kroon, 1972; Stairs \& Blick, 1979) where none may have been reported otherwise, the central issue addressed by this study has remained moot. 


\section{CHAPTER VI}

\section{SUMMARY OF CHAPTERS I THROUGH V}

At this point, a summary of the preceding chapters may be useful.

We use waking experience as a baseline against which to compare dreams. Dreams have been described as very similar or "continuous" and quite different, discontinuous, or "compensatory" with waking experience. In any case, mentation during both states seems to vary in consonance with individual personality structure.

Within the dreaming versus waking experience framework, descriptions of the nature of dream emotions constitute a very mixed bag indeed. While some researchers are puzzled that dream emotions seem fewer and more dysphoric than expected, others see dreams as mechanisms for venting emotions, and still others believe that dream emotions "parallel" waking affect. Studies which actually compare measures from both states find that dream emotions are less frequent, more unpleasant, and may even reflect different aspects of experience.

The nature of emotions per se is a critical factor which has been essentially ignored by dream researchers. Arnold's model lends itself to the consideration of dream emotions, especially as they relate to sleep physiology. Within this paradigm, restricted extrinsic perceptual data and limited recourse to voluntary physical action during sleep may be reflected in a limited incidence of emotions and a predominance of emotions which suggest confusion and anxiety in dream reports. 
The emotional dimensions observed in any dream study involve a complex mix of subject and procedural variables. Factors such as an individual's personality, sex, and whether or not he or she typically remembers dreams dictate results. Where, when, and how dream accounts are obtained and a dreamer's pre-sleep experiences also characterize reports. Altogether, the observed frequency and quality of emotions in a dream study are as much a function of the research design as the dreamer's contribution. 


\section{CHAPTER VII}

\section{DESCRIPTION OF THE PRESENT STUDY \\ STATEMENT OF PURPOSE AND PROSPECTUS}

The purpose of the present study is to determine if the incidence or kinds of apparent emotions in dream reports differs from emotions in reports of waking experiences. To achieve a more homogeneous sample, all subjects were female. Since mentation across the dreaming and waking states may vary in consonance with individual personality structure (Foulkes \& Rechtschaffen, 1964; Foulkes et al., 1966; Vogel et al., 1966; Starker, 1973, 1974, 1977; Cohen, 1974; Fisher \& Greenberg, 1977; Voge1, 1978) subjects served as their own controls. Frequency counts for five classes of emotions were scored independently by two judges according to Hall and Van de Castle's (1966) scale. Both total frequencies and rates of emotions per 100 words of report, for waking experience and dream reports from contiguous evening-morning time frames, were compared for statistically significant differences.

In general, these data suggest that the amounts and kinds of emotions in these dream and waking experience reports do not differ. However, there is some indication that this may not be the case for all individuals. 
METHOD

Subjects

Nineteen women students, nine enrolled in an evening class in Personal and Social Adjustment (PSA) and 10 in an afternoon class in the Psychology of Women (PW), at Portland State University were selected as subjects on the basis of a Sleep and Dream Habits Questionnaire adapted from Lehto (1980) (Appendix A). Of the nine individuals who completed the project, two were from the PSA and seven from the PW class.

In an attempt to insure the subject's privacy, no personal or demographic data other than name, address, phone number, and age were solicited. Since subject's anonymity was considered important, no attempt was made to identify the nine women who finished the study. It is, therefore, impossible to distinguish them from the 10 who did not. The PSA group ranged in age from 19 to 32 with a mean age of 24.4 and a standard deviation of 4.58. The PW women were from 18 to 43 years old. Their mean age was 30.2 years with a standard deviation of 7.41 . The subject selection criteria were people who purported to remember their dreams at least twice during the previous two weeks and were interested in participating in the study. The following are data from the Sleep and Dream Habits Questionnaires of the 19 individuals who started the project: Five were using a prescribed medication; fourteen were not. One fell asleep within 5 minutes, six within 5 to 10 minutes, seven within 10 to 15 minutes, four within 15 to 20 minutes, and one took more than 20 minutes after going to bed. One slept less 
than five hours; two, five to six hours; and sixteen, seven to eight hours per night. Ten reported having a regular bedtime and waking time and nine did not. Five went to bed about 10 P.M., ten about 11 P.M., and four about 12 A.M. Six got up about 6 A.M., 10 about 7 A.M., and one each at about 8, 9, and 10 A.M. Five recalled having been dreaming just about every morning, seven most mornings, three about every other morning, and four about two mornings a week during the two week period preceding the study. Two recorded just about every dream, one recorded one dream, and sixteen had not recorded a dream during the previous two weeks. One remembered a few parts, eight many parts, seven most parts, and three reported remembering their dreams in great detail. One was a little interested, five moderately interested, and thirteen extremely interested in dreams. One was a little interested, eight moderately interested, and ten extremely interested in participating in the project.

A11 19 subjects signed an Informed Consent Form (Appendix B) required by Portland State University.

The nine subjects who completed the study were paid $\$ 10$ each when they turned in their reports to the experimenter. The seven PW subjects were granted extra class credit for participating. These considerations were offered to all subjects upon selection.

\section{Procedures}

Data Collection. Subject selection and data collection were conducted at Portland State University during the winter term of 1983 . The procedure was essentially the same for both the PSA and PW classes. It began with the experimenter reading the following statement to the class: 
I am Dean Conklin. For my Master's thesis I am doing a study which requires obtaining written reports of dreams and waking experiences from female subjects. I need some women who are willing to write down some of their waking experiences and dreams for me. This will be done at home and will require a few minutes of your time each evening and morning for two weeks. You need not report events which you consider to be too personal in nature. Your name will not be used on the reports. You will be referred to by numbers only. I am not concerned with knowing who wrote a given report. I will pay those who complete the project $\$ 10$ each. I need to have those of you who are willing to do so fill out a questionnaire. This will take about two minutes. People who fill out questionnaires may not necessarily be selected to participate in the study. With your permission, I would like to meet with the selected subjects for about 15 minutes at the end of this class one week from today. At that time I will explain the project in more detail; I will ask you to sign a form consenting to participate as a subject in the study, and $I$ will hand out some materials which you will use. The two week data collection period will begin January 23 and end February 6. Are there any questions?

Questions regarding what was expected in the reports were answered in a non-directive, open-ended fashion. Subjects were advised to report or not report whatever they felt was appropriate within the bounds of the experiment and that these bounds would be explained in greater detail later.

Thirty-two women completed questionnaires. Individuals who remembered having dreamed less than twice during the past two weeks, did not recall dreams "at al1" clearly, or were "not at a11" interested in dreams or in participating in the project were not selected. After selection, the experimenter met with the PSA and PW subject groups separately. They were told that the purpose of the study was to evaluate and analyze written accounts of dreams and waking experiences. They were reminded that their reports would remain anonymous and told that the project would be explained in detail after the reports were 
returned to the experimenter. Subjects then signed the Informed Consent Form (Appendix B).

Each subject received a 10 by 12 inch envelope containing 50 sheets of eight and one-half by eleven inch, white, ruled, writing paper; 28 four by nine and one-half inch, white envelopes; a black ink, ball point pen; and an instruction sheet (Appendix C). The larger envelopes were stamped with the subject's number, one through nineteen, in the upper right hand corner. The smaller envelopes in each packet had this same number stamped in the upper right hand corner and a date stamped in the upper left hand corner. The dates ran consecutively from January 23, 1983 to February 6, 1983. For all subjects, one envelope for each date, except the last, February 6, 1983, had the notation "P.M.: SIGNIFICANT EXPERIENCES, PAST 4 HOURS" stamped after the date. Beginning January 24, 1983 and every second day thereafter, even numbered subjects received one envelope with "A.M.: DREAMS" stamped after the date. These same subjects had one envelope for every other day beginning January 25, 1983 which was stamped "A.M.: SIGNIFICANT EXPERIENCES, LAST 4 HOURS YESTERDAY" following the date. This pattern was reversed for odd numbered subjects with the latter notation beginning on January 24, 1983 and every other day thereafter, and "A.M.: DREAMS" beginning on January 25, 1983 and alternate mornings. January 23 had no "A.M." reports envelope, and February 6 had no "P.M." reports envelope.

The experimenter went over the packet materials, read and discussed the intructions sheet, and answered questions with the subject groups from the two classes separately. 
The report process, as outlined in the instruction sheet, proceeded as follows: All subjects started recording on January 23, 1983. Each day for 14 consecutive days, within one-half hour before going to sleep, each subject was to write about her experiences during the preceding four hours of that day. During this same period of time, within one-half hour after waking up every other day, beginning January 24,1983 , even numbered subjects described any dreams which came to mind from the previous night. After awakening on alternate days, those same subjects again described their experiences during the last four hours of the preceding evening. Odd numbered subjects followed the same format except that they wrote about dreams after awakening every other day beginning January 25, 1983 and described the previous evening's events on alternate mornings. Figure 1 diagrans the report process for odd and even numbered subjects. The subjects recorded the date, time, and their number at the beginning of each report.

When completed, each report was to be sealed in its envelope and the envelope returned to the packet. If subjects complied with this requirement, they were unable to reread or change completed reports.

Reports and other materials were collected from the PSA subjects on February 7, 1983 and the PW subjects on February 8, 1983. Two PSA subjects, numbers three and five, and seven PW subjects, numbers 11,12 , $13,14,16,18$, and 19, turned in complete sets of reports. These subjects were paid and the project and its purpose were explained in detail immediately after the materials were returned to the experimenter. 


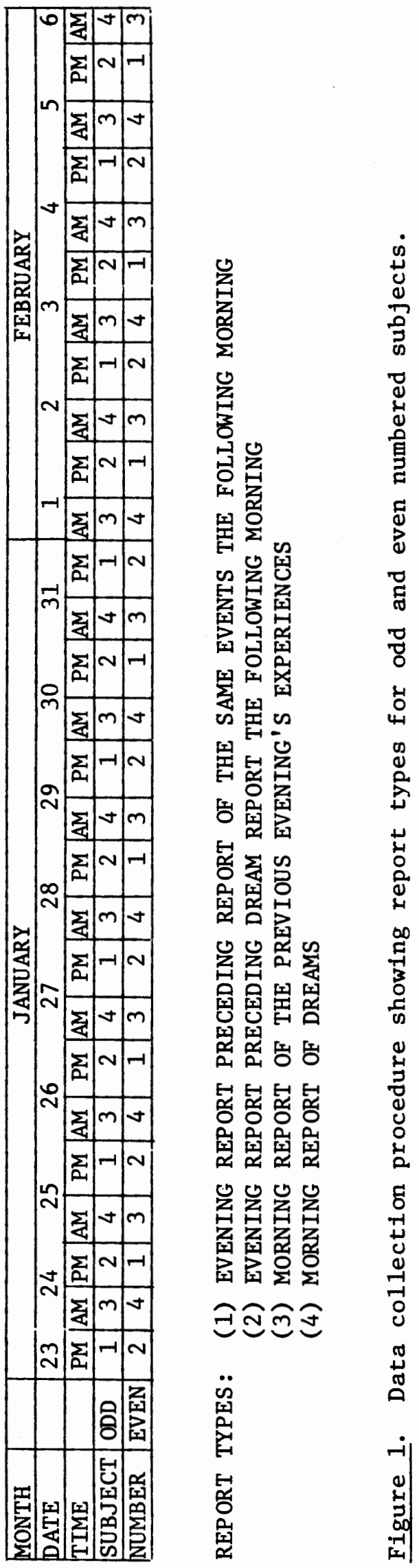


Each written report was assigned a four digit number for identification. The first two digits were the subject's number and the second two the sequential number of the particular report starting with the first evening report as number 01 . For example, subject number three's reports were numbered: 0301, 0302, 0303, etc.

All reports from all subjects were then compiled in a semirandomized order in a three ring binder. They were typed, double-spaced, on eight and one-half inch, white, typing paper with the appropriate identification number double-spaced immediately above each report at the left hand margin. The reports were typed verbatim as written by the subject. No report was modified, corrected, or changed in any way from its original form. When the handwriting was illegible, the typist placed an ellipsis of three periods in parentheses.

Scoring. The typed reports were scored for the five classes of emotions and according to the standards described by Hall and Van de Castle (1966, pp. 110-114) for "The Classification and Scoring of Emotions" in dream reports. These classes include: anger, apprehension, happiness, sadness, and confusion. The salient aspects of each class are discussed along with some representative terms, scoring procedures, and examples. Emotions are scored when specific words connoting emotion, often verbs and adjectives, occur in a dream report. Emotions may be scored for the dreamer and other dream characters. This convention was followed in the present study; but in keeping with its primary focus, the emotions expressed by all characters were combined for each class and for all emotions together in the data analysis reported. Differences in intensity of emotion are not identified in the scale. 
Hall and Van de Castle define dreams as "that which a person reports when he is asked to relate a dream, excluding statements which are comments on or interpretations of the dream" (p. 18). Norms were developed from 1,000 dream reports, five of which were submitted by each of 100 female and 100 male undergraduate college students as an assigned class project. These were "home" or nonlaboratory dreams. No dream was less than 50 or more than 300 words in length. Subject's ages ranged from 18 to 25 .

Scorer reliability for two judges was assessed using 100 dreams. Total emotions scored were 78 and 70 respectively. For specific classes of emotions, total ranged from 27 to 20 (apprehension) to 13 and 13 (happiness) for the two judges. The interrater correlation for numbers of emotions scored over groups of 10 dreams was .76 (p. 155).

In a contemporary review of dream measurement scales, Winget and Kramer (1979) cite eight studies between 1968 and 1972 which used this sytem. One, Sandler, Kramer, Trinder, and Fishbein (1970), assessed interrater reliability and found consistent rater disagreement as if the raters were "operating under different assumptions" (Winget \& Kramer, p. 38).

In the present study, two female graduate students at Portland State University were paid $\$ 100$ each to score the reports. Before seeing the data, they studied the scoring procedures outlined in Chapter 10 and Appendix B of Hall and Van de Castle (1966). They also practiced scoring on dreams related in Cartwright (1977). 
Both raters received the following items bound in identical three ring binders: (1) a summary list of Hall and Van de Castle's scoring criteria (Appendix D), (2) some "Notes for Scorers" (Appendix E), (3) tally sheets for scoring emotions (Appendix F), and (4) copies of the typed reports in the same semi-randomized order. The scorers entered the report number and a tally mark in the appropriate block on the tally sheet for each instance of emotion which she identified. All scoring materials were returned to the experimenter during the first week of April 1983.

The experimenter compiled the ratings by subject-report number and counted the words in each report. When dream reports contained more than one dream, the frequency counts of words and emotions for all dreams together were used.

Hall and Van de Castle suggest that since frequencies of some "experiences will depend, to some degree, on the length of the dream -. [ [events] should be computed for dreams of equal length or for frequencies per words of the dream text (rates)" (p. 13). At the same time, since Pearson's $\underline{r}$ comparisons of frequencies of emotions with words of report in the present data are small, $\underline{r}=.543, \underline{p}<0.000$, for rater $A$ and $\underline{r}=.506, p<0.000$, for rater $B$, frequencies of emotions may not be related to report length. Hence, data analysis are expressed in terms of both frequencies and rates whenever appropriate. In this study, "rate" indicates the frequency count of a given class of emotions or all classes of emotions per 100 words of a given report. 
RESULTS

$\underline{\text { Raters }}$

Table I summarizes the raters' data over all $\underline{N}=252$ reports and gives Pearson's $\underline{\mathbf{r}}$ values for interrater correlations on respective parameters. A $\underline{t}$-test of the difference in the mean numbers of emotions scored per report for the two raters over all reports reveals that rater $B$ identified significantly more emotions than did rater A: mean difference $=-0.119$, standard deviation $=0.784, \underline{t}=-2.41, p<0.017$.

\section{TABLE I}

SUMMARY OF FREQUENCY COUNTS FOR FIVE CLASSES OF EMOTIONS AND TOTAL EMOTIONS FOR $\mathrm{N}=252$ REPORTS AND

PEARSON'S $\underline{r}$ VALUES FOR TWO RATERS

RATER A

RATER B

\begin{tabular}{lccccccc}
\hline EMOTION & FREQUENCY & MEAN & SD & FREQUENCY & MEAN & SD & PEARSON'S r $^{*}$ \\
\hline ANGER & 38 & 0.151 & 0.439 & 35 & 0.139 & 0.410 & 0.770 \\
APPREHENSION & 62 & 0.246 & 0.531 & 63 & 0.250 & 0.494 & 0.813 \\
CONFUSION & 31 & 0.123 & 0.405 & 38 & 0.151 & 0.490 & 0.709 \\
HAPPINESS & 104 & 0.413 & 0.734 & 134 & 0.532 & 0.885 & 0.765 \\
SADNESS & 37 & 0.147 & 0.453 & 32 & 0.127 & 0.409 & 0.781 \\
ALL & 272 & 1.079 & 1.423 & 302 & 1.198 & 1.510 & 0.859 \\
\hline
\end{tabular}

*Probability $\underline{r}=0$ is 0.000 in all cases.

Table II, which will be discussed later, gives the nonsignificant results and significant $\underline{t}$ values at a chance $p<0.05$ for correlated means t-tests of the difference in mean frequencies and rates of emotions comparing evening with subsequent morning reports for all subjects and both raters. Phi coefficients computed where significant $\underline{t}$ values equal 0 and nonsignificant values equal 1 in Table II, comparing rater A with rater $B$, give $\underline{p h i}=0.438$ for frequencies and phi $=0.125$ for rates of emotions. In other words, rater agreement regarding significant 
$\underline{t}$ values for these data are negligible. In addition, if only those cases are considered where either one or both raters' $\underline{t}$ value is significant, things go from bad to worse: for frequencies phi $=0.50$, for rates phi $=-1.00$. In the first case, the raters disagreed as often as not; in the latter, they always disagreed.

TABLE II

T- TESTS OF DIFFERENCES IN CORRELATED MEAN FREQUENCIES AND RATES OF TOTAL EMOTIONS PER REPORT COMPARING TYPE 1

WITH TYPE 3 AND TYPE 2 WITH TYPE 4 REPORTS

\begin{tabular}{|c|c|c|c|c|c|c|c|c|c|}
\hline \multicolumn{9}{|c|}{} & \multicolumn{9}{c|}{ RATER A } & \multicolumn{1}{c|}{ RATER B } \\
\hline & \multicolumn{2}{|c|}{ FREQUENCY } & \multicolumn{2}{|c|}{ RATE } & \multicolumn{2}{|c|}{ FREQUENCY } & \multicolumn{2}{c|}{ RATE } \\
\hline SUBJECT & PAIR & T & P & T & P & T & P & T & P \\
\hline 3 & $1-3$ & & & & & & & & \\
\hline 3 & $2-4$ & & & & & & & & \\
\hline 5 & $1-3$ & & & -2.48 & 0.048 & & & & \\
\hline 5 & $2-4$ & & & & & & & & \\
\hline 11 & $1-3$ & 2.71 & 0.035 & & & & & & \\
\hline 11 & $2-4$ & & & & & & & 2.44 & 0.050 \\
\hline 12 & $1-3$ & & & & & 2.52 & 0.045 & & \\
\hline 12 & $2-4$ & & & 2.90 & 0.027 & & & & \\
\hline 13 & $1-3$ & & & & & & & & \\
\hline 13 & $2-4$ & & & & & & & -3.10 & 0.021 \\
\hline 14 & $1-3$ & & & & & & & & \\
\hline 14 & $2-4$ & & & & & & & & \\
\hline 16 & $1-3$ & & & & & & & & \\
\hline 16 & $2-4$ & & & & & & & & \\
\hline 18 & $1-3$ & & & & & & & & \\
\hline 18 & $2-4$ & 3.29 & 0.017 & & & 4.04 & 0.007 & & \\
\hline 19 & $1-3$ & & & & & & & & \\
\hline 19 & $2-4$ & & & & & & & & \\
\hline
\end{tabular}

*Pairs: (1-3) Evening report with next morning's report of prior evening's experiences

(2-4) Evening report with next morning's report of dreams Blank cells indicate $\underline{t}$ values with chance $p>0.05$. $\mathrm{All} \mathrm{DF}=6$ 


\section{Reports}

Each of nine subjects returned 28 reports for a total of $\underline{N}=252$. Each set of 28 reports included seven of each "type." Figure 1 shows the format of the raw data. Table III gives mean word counts for the four types of reports and the results of differences in correlated means $t$-tests comparing evening with the following morning's report (type 1 versus 3 and type 2 versus 4 ) and comparing morning reports of previous evening's experiences with the next morning's dream reports (type 3 versus 4). Mean evening report was significantly longer than subsequent morning report of the same experiences. The mean dream report was signficiantly longer than both the preceding evening and alternate morning reports.

TABLE III

T-TESTS OF DIFFERENCES IN CORRELATED MEAN WORD COUNTS COMPARING REPORT TYPES USING DATA FROM ALL SUBJECTS

\begin{tabular}{crrccccc}
\hline & MEAN & \multicolumn{7}{c}{ MEAN } \\
TYPE* & WORDS & S.D. & DIFFERENCE & S.D. & T & P & D.F. \\
\hline 1 & 114.73 & 64.00 & & & & & \\
3 & 73.38 & 44.28 & 41.35 & 53.82 & 6.10 & 0.000 & 62 \\
\hline 2 & 119.57 & 74.68 & & & & & \\
4 & 171.75 & 149.76 & -52.17 & 160.25 & -2.58 & 0.012 & 62 \\
\hline 3 & 73.38 & 44.28 & & & & & \\
4 & 171.75 & 149.76 & -98.37 & 155.91 & -5.01 & 0.000 & 62 \\
\hline
\end{tabular}

*Report Types: (1) Evening report preceding report of the same events the following morning

(2) Evening report preceding dream report the following morning

(3) Morning Report of the previous evening's events

(4) Morning report of dreams

Table II presents the crux of findings as far as differences in numbers of emotions in evening versus morning reports are concerned. T-tests were calculated to identify significant differences in mean total 
frequencies and rates of emotions between type 1 versus 3 and type 2 versus 4 reports for each subject. The resulting two sets of 18 comparisons for each rater include only four significant differences in each set for a total of eight significant findings. The $\underline{t}$ value was significant for both raters in only one case. In six instances evening and in two cases morning reports expressed more emotions. In no case were both the frequency and rate $t$ values different from the chance level.

In order to tell if a given class of emotions was identified more often in evening or morning reports, and hence that one or the other was more emotionally dysphoric, t-tests for differences between correlated means were evaluated for each class of emotions comparing type 1 versus 3 and type 2 versus 4 reports for each subject-rater combination and for both frequencies and rates of emotions. of these $\underline{N}=360$ comparisons, four yielded significant $\underline{t}$ values at $\mathbb{2}<0.05$. These four instances are summarized in Table IV. According to rater B, subject 13 expressed more apprehension in dreams than in waking reports the previous evening. The raters agree that subject 18 expressed a greater incidence of happiness in evening reports than in dream reports the following morning.

\section{DISCUSSION OF RESULTS}

Rater disagreement is the most apparent Achilles' heel of this study. The interrater correlations for frequency counts over each class of emotions and all emotions, while modest, may be acceptable. It is 
TABLE IV

T-TESTS OF DIFFERENCES IN CORRELATED MEAN FREQUENCIES OR RATES, WHERE $P<.05$, FOR FIVE CLASSES OF EMOTIONS COMPARING EVENING AND SUBSEQUENT MORNING REPORT TYPES**

\begin{tabular}{|c|c|c|c|c|c|c|c|c|c|c|c|c|}
\hline RATER & $\mathrm{s}$ & \begin{tabular}{|l|} 
EMOTION \\
\end{tabular} & TYPE* & $\begin{array}{c}\text { RATE (R)/ } \\
\text { FREQUENCY (F) }\end{array}$ & $\mathrm{N}$ & MEAN & S.D. & $\begin{array}{c}\text { MEAN } \\
\text { DIFFERENCE }\end{array}$ & S.D. & $\mathrm{T}$ & $P$ & D.F \\
\hline B & 13 & APPREHENSION & \begin{tabular}{|l|}
2 \\
4 \\
\end{tabular} & $\begin{array}{l}F \\
F \\
\end{array}$ & $\begin{array}{l}0 \\
6 \\
\end{array}$ & \begin{tabular}{|c|}
0 \\
0.857 \\
\end{tabular} & 0.690 & -0.857 & $|0.690|$ & -3.29 & 0.017 & 6 \\
\hline B & 13 & APPREHENSION & $\begin{array}{l}2 \\
4 \\
\end{array}$ & $\begin{array}{l}\mathrm{R} \\
\mathrm{R} \\
\end{array}$ & $\begin{array}{l}0 \\
6 \\
\end{array}$ & $\begin{array}{c}0 \\
0.299 \\
\end{array}$ & 0.230 & -0.299 & 0.230 & -3.44 & 0.014 & 6 \\
\hline A & 18 & HAPPINESS & $\begin{array}{l}2 \\
4 \\
\end{array}$ & $\begin{array}{l}\mathrm{F} \\
\mathrm{F} \\
\end{array}$ & $\begin{array}{l}5 \\
0 \\
\end{array}$ & \begin{tabular}{|c|}
0.714 \\
0 \\
\end{tabular} & 0.756 & 0.714 & 0.756 & 2.50 & $|0.047|$ & 6 \\
\hline A & 18 & & $\begin{array}{l}2 \\
4\end{array}$ & $\begin{array}{l}\mathrm{F} \\
\mathrm{F}\end{array}$ & $\begin{array}{r}10 \\
0 \\
\end{array}$ & $\begin{array}{c}1.429 \\
0\end{array}$ & 1.397 & 1.429 & 1.397 & 2.71 & 0.035 & 6 \\
\hline
\end{tabular}

* See Figure 1 for report types

**P > . 05 for all similar comparisons for all subjects and both raters 
clear, however, that rater B scored significantly more emotions than did rater A. It seems that rater A exercised more stringent, or rater B more relaxed standards in identifying an emotion. The phi coefficients show a dramatic lack of agreement between the raters with regard to significant differences in emotions expressed in evening and morning reports. It is impossible to say if these disagreements derive from the Hall and Van de Castle scale itself, the manner in which it was employed in the present study, or some personal variable related to the particular raters. Better agreement may have been achieved had the raters been more extensively trained. While these findings do not necessarily parallel Sandler's et al. (1970) contention that their raters operated "under different assumptions" (Winget \& Kramer, 1979, p. 38), rater agreement was a problem in both cases. As a consequence, all data analyses are problematic and must be considered with this caveat in mind. Different report types differ in mean numbers of words per report. Dream reports are longer than both previous evening reports and alternate morning reports. Evening reports are longer than reports of the same events the following morning. Reporting the prior evening's activities a second time was redundant and may have been less interesting to the subjects than the other two report types. By the same token, dream reports may have been more interesting and hence subjects wrote more about them. This greater length, however, does not coincide with an increased number of emotions per report.

In the overwhelming majority of cases, the incidences of total emotions and of each specific class of emotions in evening and morning 
reports do not differ. In the very few cases where a difference is identified, the two raters almost never agree.

\section{CONCLUSIONS}

This study affords very little evidence to support the contention that dreams are not continuous with waking experience. The data seem to contradict previous assertions (Calkins, 1893; Weed \& Hallam, 1896; Bentley, 1915; Hall \& Van de Castle, 1966; Snyder, 1970; Kramer et al., 1971; Hartshorn et al., 1977) that dreams express fewer or more unpleasant emotions than might be expected. The present design, unlike most others, incorporates reports of waking experience as a basis of comparison without which the central questions are very difficult to evaluate operationally. In the present perspective, hypotheses supporting the discontinuity position would have to be discounted for most subjects.

On the other hand, data from subjects 13 and 18 are consistent with the argument that dreams express more dysphoric or less pleasant emotions. Subject 13 expressed more apprehension in her dream reports than in waking experience reports the evening before. Subject 18 often described happiness in daytime experiences but never in dreams. The fact that significant results of these kind appeared for only two subjects may well reflect findings previosly cited (Starker, 1973, 1974, 19744; Cohen, 1974; Fisher and Greenberg, 1977; Foulkes \& Rechtschaffen, 1964; Foulkes et al., 1966; Vogel et a1., 1966; Voge1, 1978) that the affective content of dreams and fantasy life is an idiographic matter. Some people's fantasies are colorful, others' are not. 
This study exhibits at least two obvious flaws: the small number of subjects and the low degree of interrater agreement. If more subjects had been studied, the findings may have been different. More interrater consistency would have placed the results in a much less equivocal position.

To summarize, the vast bulk of the present findings support the notion that dreams are essentially continuous with waking experience as far as both numbers and kinds of emotions are concerned. There is, however, a suggestion that dreams might be less pleasant for some individuals than are their waking experiences. 


\section{REFERENCES}

Arkin, A. M., Antrobus, J. S., \& Ellman, S. J. (Eds.). The mind in sleep: Psychology and psychophysiology. Hillsdale, N.J.: Lawrence Erlbaum Assoc., 1978.

Arkin, A. M. \& Antrobus, J. S. In Arkin, A. M. et al., 1978.

Arnold, M. B. Emotion and personality, vol. I: Psychological aspects, vo1. II : Neurological and physiological aspects. New York: Columbia Univ. Press, 1960.

Arnold, M. B. (Ed.). Feelings and emotions: The loyola symposium. New York: Academic Press, 1970.

Aserinsky, E. \& Kleitman, N. Regularly occurring periods of eye motility and concomitant phenomena during sleep. Science, 1953, $118,273-274$.

Barber, B. Factors underlying individual differences in rate of dream reporting. Psychophysiology, 1969, 6, 247-248. (Abstract)

Beck, A. T. Dreams as compared to other forms of fantasy. In M. Kramer, R. M. Whitman, B. J. Baldridge, \& P. H. Ornstein (Eds.), Dream psychology and the new biology of dreaming. Springfield, I11.: Charles C. Thomas, 1969.

Bentley, M. The study of dreams. A method applied to the seminary . American Journal of Psychology, 1915, 26 196-210.

Bonime, W. The clinical use of dreams. New York: Basic Books, 1962 .

Breger, L. Function of dreams. Journal of Abnormal Psychology Monograph, 1967, 72 (5, Whole No. 641).

Calkins, M. W. Statistics of dreams. American Journal of Psychology, $1893,5,311-343$.

Cannon, W. B. Bodily changes in pain, hunger, fear and rage: An account of recent researches into the function of emotional excitement (2nd ed.). New York: Appleton, 1929.

Cartwright, R. D. Dreams as compared to other forms of fantasy. In M. Kramer, R. M. Whitman, B. J. Baldridge, \& P. H. Ornstein (Eds.), Dream psychology and the new biology of dreaming. Springfield, I11.: Charles C. Thomas, 1969.

Cartwright, R. D. Night Life. New Jersey: Prentice-Hall, 1977. 
Cartwright, R. D. \& Kaszniak, A. The social psychology of dream reporting. In A. Arkin, J. Antrobus, \& S. J. Ellman (Eds.), The mind in sleep: Psychology and psychophysiology. Hillsdale, N.J.: Lawrence ErIbaum Asso., 1978.

Cohen, D. B. Frequency of dream recall estimated by three methods and related to defense preference and anxiety. Journal of Consulting and Clinical Psychology, 1969, 33, 661-667. (a)

Cohen, D. B. Validity of dream report collection via non-laboratory sleep interruption. Psychophysiology, 1969, 6,251 . (Abstract)

Cohen, D. B. Dream recall and total sleep time. Perceptual and Motor Skills, $1972, \underline{34}, 456-458$. (a)

Cohen, D. B. Failure to recall dream content: Contentless vs. dreamless reports. Perceptual and Motor Skills, 1972, 24, 1000-1002.

Cohen, D. B. Toward a theory of dream recall. Psychological Bulletin, $1974, \underline{81}, 138-154$.

Cohen, D. B. \& MacNeilage, P. R. Dream salience and postsleep interference factors that differentiate frequent and infrequent dream recallers. Sleep Research, 1973, 2.

Corriere, R., Hart, J., Karle, W., Binder, J., Gold, S., \& Woldenberg, L. Toward a new theory of dreaming.' Journal of Clinical Psychology, $1977, \underline{33}(3), 807-820$.

Dement, W. C. The biological role of REM sleep. In W. B. Webb (Ed.), Sleep: An active process. Glenview, Ill.: Scott Foresman, 1973.

Dement, W. \& Kleitman, N. The relation of eye movement during sleep activity: An objective method for the study of dreaming. Journal of Experimental Psychology, 1957, 53, 339-346.

Dewan, E. M. The programming (P) hypothesis for REM's. (Physical Science Research Papers, No. 388, Project 5628) Air Force Cambridge Research Lahoratories, 1969.

Domhoff, B. Home dreams versus laboratory dreams. In M. Kramer, R. M. Whitman, B. J. Baldridge, \& P. H. Ornstein (Eds.), Dream psychology and the new biology of dreaming, Springfield, I11.: Charles C. Thomas, 1969.

Edney, C. S. A comparison of three measures of waking fantasy. Unpublished master's thesis, Portland State University, 1980. 
Ellman, S. J. Editors forward in A. Arkin, J. Antrobus, \& S. J. Ellman (Eds.), The mind in sleep: Psychology and psychophysiology. Hillsdale, N. J.: Lawrence Erlbaum Assoc., 1978.

Fisher, S. \& Greenberg, R. P. The scientific credibility of Freud's theories. New York: Basic Books, 1977.

Foulkes, W. D. Dream reports from different stages of sleep. Journal of Abnormal and Socia1 Psychology, 1962, 65, 14-25.

Foulkes, D. The psychology of sleep. New York: Scribner, 1966.

Foulkes, D. Nonrapid eye movement mentation. Experimental Neurology, 1967, (Supplement 4), 28-38.

Foulkes, D. \& Fleisher, S. Mental activity in relaxed wakefulness. Journal of Abnormal Psychology, 1975, 84(1), 66-75.

Foulkes, D. \& Rechtschaffen, A. Presleep determinants of dream content: Effects of two films. Perceptual and Motor Skills, 1964, 19, 983-1005.

Foulkes, D., Spear, P. S., \& Symonds, J. D. Individual differences in mental activity at sleep onset. Journal of Abnormal Psychology, $1966, \underline{71}(4), 280-286$.

Freud, S. The interpretation of dreams. In J. Strachey (Ed.), Standard edition of the complete psychological works of Sigmund Freud (Vo1. 4). London: Hogarth Press, 1960.

Goodenough, D. R. Some recent studies in dream recall. In H. A. Witkin \& H. B. Lewis (Eds.), Experimental studies of dreaming. New York: Random House, 1967.

Goodenough, D. R. Dream recall: History and current status of the field. In A. Arkin, J. Antrobus, \& S. J. Ellman (Eds.), The mind in sleep: Psychology and psychophysiology. Hillsdale, N. J.: Lawrence Er1baum Assoc., 1978.

Goodenough, D. R., Lewis, H. B., Shapiro, A., Jaret, L., \& Sleser, F. Dream reporting following abrupt and gradual awakenings from different types of sleep. Journal of Personality and Social Psychology, 1965, 2, 170-179.

Goodenough, D. R., Shapiro, A., Holden, M., \& Steinschribed, L. A comparison of "dreamers" and "nondreamers": Eye movements, electroencephalograms, and the recall of dreams. Journal of Abnormal and Social Psychology, 1959, (Nov.) 59, 295-302. 
Goodenough, D. R., Witkin, H. A., Koulack, D., \& Cohen, H. The effects of stress films on dream affect and on respiration and eye-movement activity during rapid-eye-movement sleep. Psychophysiology, 1975, (May) 12(3), 313-320.

Gottschalk, L. A., \& Gleser, G, C. The measurement of psychological state through the content analysis of verbal behavior. Los Angeles: University of California Press, 1969.

Gottschalk, L. A., Winget, C. M. , \& Gleser, G. C. Manual of instructions for using Gottschalk-Gleser content Analysis scales.

Los Angeles: University of California Press. 1969.

Ha11, C. The meaning of dreams. New York: McGraw-Hil1, 1966.

Hall, C. S., \& Van de Castel, R. L. The content analysis of dreams. New York: Appleton-Century-Crofts, 1966

Hart, J., Corriere, R., \& Binder, J. Going sane: An introduction to feeling therapy. Los Angeles: Phoenix Books, 1975.

Hartshorn, K., Corriere, R., Karle, W. Switzer, A., Hart, J., Gold, S., $\&$ Binder, J. A reapplication of the process of scoring system for dreams. Journal of Clinical Psychology, 1977, 33(3), 844-848.

Hunt, J. McV., Cole, M. W., \& Reis, E. E. Situational cues distinguishing anger, fear, and sorrow. Américan Journal of Psychology, $1958,71,136-151$.

Isaacs, D. Daydreaming and mind-wandering: A construct validation. Unpublished doctoral dissertation, City University of New York, 1975.

Izard, C. E. Anxiety: A variable combination of interacting fundamental emotions. In C. D. Spielberger (Ed.), Anxiety: Current trends in theory and research. (Vo1. 1). New York: Adademic Press, 1972.

James, W., \& Lange, C. G. The emotions. Baltimore, Md.: Williams and Wilkins, 1922 .

Jones, R. M. The new psychology of dreaming. New York: Grune \& Stratton, 1970 .

Kramer, M., Winget, C., \& Whitman, R. M. A city dreams: A survey approach to normative dream content. American Journal of Psychiatry, 1971, 127, 1350-1356.

Kraner, M., Whitman, R. M., Baldridge, B. J., \& Ornsteing, P. H. (Eds.). Dream psychology and the new biology of dreaming. Springfield, I11.: Charles Thomas, 1969. 
Kroon, H. R. An idiographic study of affective interpersonal reactions in waking life and recalled dreams (Doctoral dissertation, Columbia University, 1972). Dissertation Abstracts International, 1973 , $34(1-B), 416 B-417 B$.

Lehto, G. N. D. A cognitive-behavioral approach to the control of dream content. Unpublished master's thesis Portland State University, 1980.

Lewis, H. B., Goodenough, D., Shapiro, A., \& Sleser, I. Individual differences in dream recall. Journal of Abnormal Psychology, 1966, 71, 52-59.

MacNeilage, P. F., Cohen, D. B., \& MacNeilage, L. A. Subjects' estimates of sleep talking propensity and dream recall. Journal of Consulting and Clinical Psychology, 1972, 39, 341.

Moruzzi, G. Active processes in the brain stem during sleep. Harvey Lecture Series, 1963, 58, 233-297.

Moruzzi, G. General discussion in Aspects anatomo-fonctionnels de la physiologie du sommeil, acter du colloque international sur les spects anatiomo-fonctionnels de la physiologie du sommeil. Lyon, Fr.: Colloques Internationauz du Centre National de la Recherche Scientifique, No, 127, 1965.

Pivik, R. T. Tonic states and phasic events in relation to sleep mentation. In A. Arkin, J. Antrobus, \& S. J. E11man (Eds.), The mind in sleep: Psychology and psychophysiology. Hillsdale, N. J.: Lawrence Erlbaum Assoc., 1978.

Plutchik, R. Emotions, evolution, and adaptive processes. In M. B. Arnold (Eds.), Feelings and emotions: The loyola symposium. New York: Academic Press, 1970.

Ruckmick, C. A. The psychology of feeling and emotion. New York: McGraw-Hi11, 1936.

Sampson, H. Discussion of Domhoff, B. In M. Kramer, R. M. Whitman, B. J. Baldridge, \& P. H. Ornstein (Eds.), Dream psychology and the new biology of dreaming. Springfield, I11.: Charles C. Thomas, 1969.

Sandler, L., Kramer, M., Trinder, J., \& Fishbein, H. Interlaboratory reliability of the Hall-Van de Castle character, social interaction, activities, and emotions scales. Psychophysiology, 1970, 7, 333-334. (APSS Abstract)

Schachter, S. The psychology of affiliation. Stanford, Calif.: Stanford University Press, 1959. 
Schachter, S. The assumptions of identity and peripheralist-centralist controversies in motivation and emotion. In M. B. Arnold (Ed.), Feelings and emotions: The loyola symposium. New York: Academic Press, 1970 .

Schachter, S. \& Singer, J. Cognitive, social and physiological determinants of emotional state. Psychological Review, 1962, 69(5), 379-399.

Schwartz, D. G., Weinstein, L. M., \& Arkin, A. M. Qualitative aspects of sleep mentation. In A. M. Arkin, J. S. Antrobus, S. J. Ellman (Eds.), The mind in sleep: Psychology and psychophysiology. Hillsdale, N. J.: Lawrence Erlbaum Assoc., 1978.

Shulman, B. An adlerian view. In M. Kramer, R. M. Whitman, B. J. Baldridge, \& P. H. Ornstein (Eds.), Dream psychology and the new biology of dreaming. Springfield, I11.: Charles C. Thomas, 1969.

Singer, J. L. Daydreaming: An introduction to the experimental study of inner experience. New York: Random House, 1966.

Singer, J. L. \& Antrobus, J. S. A factor analytic study of daydreaming and conceptually related cognitive and personality variables. Perceptual and Motor Skills, 1963, 17, 187-209.

Singer, J. L. \& Antrobus, J. S. Daydreaming, imaginal processes and personality: A normative study. In P. Sheehan (Ed.), The nature and function of imagery. New York: Academic Press, 1972, 175-201.

Snyder, F. The physiology of dreaming. In M. Kramer, R. M. Whitman, B. J. Baldridge, \& P. H. Ornstein (Eds.), Dream psychology and the new biology of dreaming. Springfield, I11.: Charles C. Thomas, 1969.

Snyder, F. The phenomenology of dreaming. In L. Madow, \& L. H. Snow (Eds.), The psychodynamic implications of the physiological studies of dreams. Springfield, I1l.: Charles C. Thomas, 1970.

Stairs, P. W. \& Blick, K. A. A survey of emotional content of dreams recalled by college students. Psychological Reports, 1979, $45(3), 839-842$.

Starker, S. Aspects of inner experience: Autokinesis, daydreaming, dream recall and cognitive style. Perceptual and Motor Skills, $1973,36,663-673$.

Starker, S. Daydreaming styles and nocturnal dreaming. Journal of Abnormal Psychology, 1974, 83(1), 52-55. 
Starker, S. Daydreaming styles and nocturnal dreaming: Further observations. Perceptual and Motor Skills, 1977, 45, 411-418.

Tomkins, S. Affect, imagery, and consciousness (Vo1.I). New York: Springer, 1962.

Torda, C. Observations on the effects of anxiety and anger on the content of concurrent dreams. American Journal of Clinical Hypnosis, 1975, $19(4), 253-259$.

Voge1, G. W. Sleep onset mentation. In A. M. Arkin, J. S. Antrobus, \& S. J. Ellman (Eds.), The mind in sleep: Psychology and psychophysiology. Hillsdale, N. J.: Lawrence Erlbaum Assoc., 1978.

Voge1, G., Foulkes, D., \& Trosman, H. Ego functions and dreaming during sleep onset. Archives of General Psychiatry, 1966, 14(3), 238-248.

Weed, S. C. \& Hallam, F. M. III.: A study of the dream-consciousness. American Journal of Psychology, 1896, 7, 405-411.

Weisz, R. \& Foulkes, D. Home and laboratory dreams collected under uniform sampling conditions. Psychophysiology, 1970, $\underline{6}(5), 588-596$.

Winget, C. \& Kramer, M. Dimensions of dreams. Gainesville: University of Florida Press, 1979. 
APPENDIX A

SLEEP AND DREAM-HABITS QUESTIONNAIRE

(Adapted from Lehto, 1980)

Please answer each of the following questions as accurately as you can. All of the information you provide will be kept strictly confidential.

Name:
Last
First

Address:

Street City

Phone:

Age:

For each of the following questions, indicate your answer by placing a cross $(\mathrm{X})$ in the appropriate blank.

1. Are you presently using any prescribed medication?

Yes No

2. Once you are in bed and ready to sleep, about how many minutes does it take you to fall asleep?

Less than $5 \_{ }^{5-10}{ }^{10-15}{ }^{15-20}{ }^{15}$ More than 20

3. About how many hours do you sleep each night?

Less than 5 5-6 7-8 9-10 More than 10

4. Do you have a regular bedtime and waking time?

Yes No

5. At approximately what time do you usually go to sleep?

8 PM 9PM 10PM $11 \mathrm{PM}$ $12 \mathrm{AM}$ After 12 AM 
6. At approximately what time do you usually get up each morning?

5 AM 6 AM 7 AM 8 AM 9 AM $10 \mathrm{AM}$

After 10 AM

7. During the LAST TWO WEEKS, immediately upon waking up in the morning, how often do you recall having been dreaming?

$\begin{array}{ll}\text { _ } & \text { every morning } \\ \text { just about every morning } & \text { about two mornings a week } \\ \text { most mornings of the } & \text { about one morning a week } \\ \text { week } & \text { once during the two weeks } \\ \text { about every other morning } & \quad \text { not once }\end{array}$

8. During the LAST TWO WEEKS, how often did you record (tape recorded or written) the dreams you recalled?

every remembered dream
just about every
remembered dream
every other remembered
dream

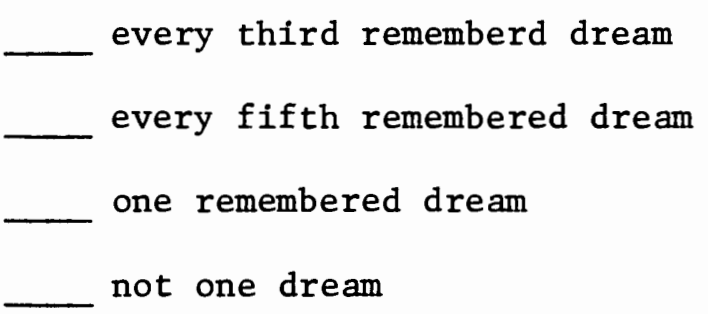

9. How clearly do you remember your dreams?

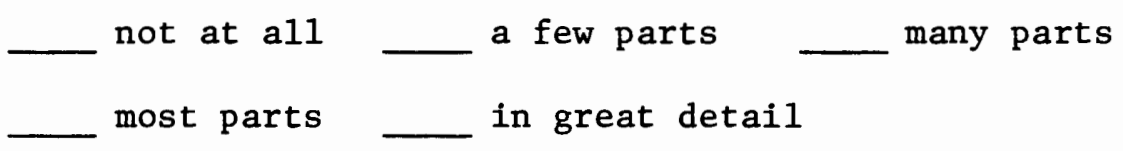

10. How interested are you in dreams? not at a11

a little moderately extremely

11. How interested are you in participating in this dream research project? not at a11 a little moderately extremely 
12. If there is anything else you would like to tell me about your dreams and/or dreaming habits, please feel free to do so here: 
APPENDIX B

INFORMED CONSENT FORM (Page 1 of 2)

I, , hereby agree to serve as a subject in the research project on written reports of waking experiences and dreams conducted by Dean Conklin, graduate student in Psychology.

I understand that the study involves writing down my significant waking experiences and dreams each morning and evening for 15 consecutive days. I will be asked to honestly report these waking experiences and dreams. I will not be required to disclose any information which I do not wish to.

It has been explained to me that the purpose of the study is to learn something of the relationship between reports of waking experiences and dreams. My participation may help to increase knowledge about dreams and dreaming. I understand that the study will be explained to me in detail after I complete the project. At that time, Dean Conklin will answer any questions which I may have about the study.

I will receive $\$ 10.00$ (ten dollars) remuneration if I complete the project.

I have been assured that all information which I give will be kept confidential and that my identity as a subject in this study will remain anonymous after the project is finished. 
I understand that I am free to withdraw from participation in this study at any time without jeopardizing my relationship with Portland State University.

I have read and understand the foregoing information. Date: Signature

If you experience problems that are the result of your participation in this study, please contact Victor C. Dahl, Office of Graduate Studies and research, 105 Neuberger Hall, Portland State University, 229-3423. 


\section{APPENDIX C}

\section{INSTRUCTIONS TO SUBJECTS}

This project will begin the evening of January 23, 1983 and will continue for 15 consecutive days until the morning of February 6, 1983. During this period, each day within one-half hour before going to sleep, please tell me about the significant experiences you have had during the preceding four hours. Within one-half hour after waking up on even numbered days, please tell me about your dreams that night. Within one-half hour after waking up on odd numbered days, please te 11 me about the significant experiences you described the previous evening.

Begin each report with the date, time, and your number. Report, in your own words, whatever comes to mind. If there are matters which you would rather not talk about, do not, but try to be as open and spontaneous as possible. Remember no one will know who wrote any report. Do not edit or rewrite. Write legibly but do not be overly concerned with mechanics such as spelling, punctuation, or grammar. Do not use names. Refer to people by their first initial only. Your envelope contains a pen, writing paper, and an envelope for each report with the date, the letters "AM" for a morning or "PM" for an evening report, the report topic, and your number printed at the top. When you finish a report, fold it, seal it in the appropriate envelope, and return the envelope to your packet. 
If you have questions call me at 656-4523 after 6:00 PM. Please do not discuss the study with anyone before you return your reports to me on February 8, 1983. I will explain the study to you in more detail at that time. After that you may discuss it with anyone if you choose to. 
APPENDIX D

SCORING CRITERIA SUMMARY

Hall and Van de Castle Scale for Emotions

Anger (AN)

Words reflecting anger:

annoyed

irritated

mad

provoked

furious

enraged

belligerent

incensed

indignant

Apprehension (AP)

Apprehension reflects discomfort because of potential danger from physical injury, punishment, ridicule, rejection, etc., emotions relate to fear, anxiety, guilt, embarrassment.

Words reflecting apprehension:

terrified

horrified

frightened

scared

worried

nervous

concerned

panicky

alarmed

uneasy

upset

remorseful

sorry

apologetic

regretful

ashamed 
Happiness (HA)

A general state of pleasant feeling tone.

Words reflecting happiness:
contented
pleased
relieved
amused
cheerful
glad
relaxed
gratified
gay
wonderfu1
elated
joyful
exhilarated

Sadness (SD)

Unhappy emotional states, not physical pain or distress.

Words reflecting sadness:
disappointed
distressed
hurt
depressed
lonely
lost
miserable
hopeless
crushed
heartbroken

Confusion (CO)

Cognitive ambiguity shading toward free-floating anxiety, frustration, depression--generally produced through confrontation with unexpected events, or inability to choose between alternatives.

Words reflecting confusion:

$$
\begin{aligned}
& \text { surprised } \\
& \text { astonished } \\
& \text { amazed } \\
& \text { awestruck } \\
& \text { mystified } \\
& \text { puzzled } \\
& \text { perplexed }
\end{aligned}
$$


(Words reflecting confusion continued):
strange
bewildered
doubtful
conflicted
undecided
uncertain

Generally, do not infer emotions from actions or settings. Emotions are usually expressed by the dreamer. Physical pain or distress is not an emotion. 


\section{APPENDIX E}

\section{NOTES FOR SCORERS}

1. The reports are typed as written by the subjects. Typist was instructued not to correct anything, (. . .) or (?) indicate typist could not read a word, (word?) indicates was not sure of word and guessed at it.

2. Some reports contain more than one dream. Score each separately. On tally sheet indicate different dreams within a report by letters "A, B, C," etc. (1425A, 1425B, etc.)

3. Do not score introductions to, explanations of, or interpretations of dreams. Example: "I was mad at $J$ when $I$ went to bed" is not scored for a dream report.

4. Potential problem areas:

"We were happy." Score for each individual if they are apparent, otherwise score for dreamer and other.

"I laughed." Would be scored as happiness.

"We had dinner out. It was wonderful." ?

"I was surprised and pleased." What emotions?

"I felt pain and anger." What is "pain"?

"I was almost sad." ? ? 
APPENDIX F

TALLY SHEET FOR SCORING EMOTIONS

Report No.

Total Words (W)

Frequency Count (F)

\begin{tabular}{|c|c|c|c|c|c|c|c|c|c|c|c|c|}
\hline & Anger & & Apprehens & ion & Confusion & & Happines & & & Sadness & & \\
\hline & $\mathrm{F}$ & $\mathrm{F} / \mathrm{W}$ & F & $\mathrm{F} / \mathrm{W}$ & F & $\mathrm{F} / \mathrm{W}$ & \begin{tabular}{|l|l} 
& $F$ \\
\end{tabular} & $\mathrm{~F}$ & & & $\mathrm{~F}$ & $\mathrm{~F} / \mathrm{W}$ \\
\hline Dreamer & & & & & & & & & & & & \\
\hline $\begin{array}{l}\text { Other } \\
\text { Females }\end{array}$ & & & & & & & & & & & & \\
\hline Males & & & & & & & & & & & & \\
\hline Others & & & & & & & & & & & & \\
\hline Tota1 & & & & & & & & & & & & \\
\hline
\end{tabular}

